\title{
The liquid fraction from hydrothermal pretreatment of wheat straw provides lytic polysaccharide monooxygenases with both electrons and $\mathrm{H}_{2} \mathrm{O}_{2}$ co-substrate
}

\author{
Riin Kont ${ }^{1}$, Ville Pihlajaniemi ${ }^{2}$, Anna S. Borisova ${ }^{2}$, Nina Aro ${ }^{2}$, Kaisa Marjamaa ${ }^{2}$, Judith Loogen ${ }^{3}$, Jochen Büchs ${ }^{3}$, \\ Vincent G. H. Eijsink ${ }^{4}$, Kristiina Kruus ${ }^{2}$ and Priit Väljamäe ${ }^{1 *}$ (D)
}

\begin{abstract}
Background: Enzyme-aided valorization of lignocellulose represents a green and sustainable alternative to the traditional chemical industry. The recently discovered lytic polysaccharide monooxygenases (LPMOs) are important components of the state-of-the art enzyme cocktails for cellulose conversion. Yet, these monocopper enzymes are poorly characterized in terms of their kinetics, as exemplified by the growing evidence for that $\mathrm{H}_{2} \mathrm{O}_{2}$ may be a more efficient co-substrate for LPMOs than $\mathrm{O}_{2}$. LPMOs need external electron donors and one key question of relevance for bioprocess development is whether the required reducing power may be provided by the lignocellulosic substrate.

Results: Here, we show that the liquid fraction (LF) resulting from hydrothermal pretreatment of wheat straw supports LPMO activity on both chitin and cellulose. The initial, transient activity burst of the LPMO reaction was caused by the $\mathrm{H}_{2} \mathrm{O}_{2}$ present in the LF before addition of $L P M O$, while the steady-state rate of $L P M O$ reaction was limited by the LPMO-independent production of $\mathrm{H}_{2} \mathrm{O}_{2}$ in the $L F . \mathrm{H}_{2} \mathrm{O}_{2}$ is an intermediate of $L F$ oxidation as evidenced by a slow $\mathrm{H}_{2} \mathrm{O}_{2}$ accumulation in $L F$, despite high $\mathrm{H}_{2} \mathrm{O}_{2}$ production rates. This $\mathrm{H}_{2} \mathrm{O}_{2}$ scavenging ability of $L F$ is important since high concentrations of $\mathrm{H}_{2} \mathrm{O}_{2}$ may lead to irreversible inactivation of LPMOs.
\end{abstract}

Conclusions: Our results support the growing understanding that fine-tuned control over the rates of $\mathrm{H}_{2} \mathrm{O}_{2}$ production and consumption in different, enzymatic and non-enzymatic reactions is essential for harnessing the full catalytic potential of LPMOs in lignocellulose valorization.

Keywords: Lytic polysaccharide monooxygenase, Hydrogen peroxide, Hydrothermal pretreatment, Wheat straw, Phenolic compounds, Oxidation, Cellulose, Chitin, Trichoderma reesei LPMO9A, Serratia marcescens LPMO10A

\section{Background}

Lignocellulosic biomass is the most abundant source of renewable carbon in Nature. Its enzyme-aided valorization to biofuels and building blocks for the chemical industry provides a green and sustainable alternative to the petroleum-based chemistry. Because of its inherent recalcitrance, the lignocellulose of plant cell walls requires mechano-chemical pretreatment to increase its

${ }^{*}$ Correspondence: priit.valjamae@ut.ee

${ }^{1}$ Institute of Molecular and Cell Biology, University of Tartu, Tartu, Estonia Full list of author information is available at the end of the article susceptibility to enzymatic conversion. Hydrothermal pretreatment does not require use of chemicals and is a simple and environment friendly method that has proven to be efficient for different biomasses [1]. The most abundant soluble by-products from hydrothermal pretreatment, and from analogous dilute acid pretreatment [1], are hemicellulose-derived mono- and oligosaccharides, and various phenolic compounds [2-4].

The enzymatic deconstruction of the polysaccharides, i.e., mainly cellulose, in pretreated lignocellulosic biomass relies on synergistic interplay between enzymes with different substrate specificities and modes of action. An 
important breakthrough in the field came in 2010 when it was discovered that a chitin-binding protein of Serratia marcescens (CBP21) is an enzyme that catalyzes oxidative cleavage of glycosidic bonds [5]. Today, these enzymes are referred to as lytic polysaccharide monooxygenases (LPMO). Since then, LPMOs with different substrate specificities have been discovered, in most kingdoms of life and it is well reported that LPMOs synergize with conventional glycoside hydrolases and improve the saccharification of biomass [6-23]. Nowadays, the LPMOs are important components of the state-of-the-art enzyme cocktails used in industrial degradation of lignocellulosic biomass [24].

LPMOs are monocopper enzymes with a flat binding surface that enables binding to the ordered crystalline regions of substrate [25]. They catalyze oxidative cleavage of glycosidic bonds by hydroxylating, either the $\mathrm{C} 1$ or the $\mathrm{C} 4$ of the scissile bond [26], resulting in the formation of a lactone or ketone, respectively [27]. According to the originally proposed mechanism [5], LPMOs require $\mathrm{O}_{2}$ as a co-substrate and delivery of two electrons from an external electron donor per glycosidic bond cleavage [27, 28]. A number of different compounds can support LPMOs with electrons [29], including phenolic compounds [7, 30-35] or lignin and its fragments [7, 31, 36-38], which are both expected to be present in liquid fractions emerging during thermochemical pretreatment of biomass [3, 39-45].

Another breakthrough in the LPMO field was made in 2017 when it was shown that LPMOs can use $\mathrm{H}_{2} \mathrm{O}_{2}$ instead of $\mathrm{O}_{2}$ [46]. Although the nature of the true cosubstrate of LPMOs is a matter of scientific debate, the fact is that $\mathrm{H}_{2} \mathrm{O}_{2}$ is used much more efficiently than $\mathrm{O}_{2}$ [46-49]. The $\mathrm{H}_{2} \mathrm{O}_{2}$-based mechanism also depends on the presence of external electron donor, but here the reductant is only needed for the initial "priming" of the $\mathrm{Cu}$ (II) resting state of the LPMO to its catalytically active $\mathrm{Cu}(\mathrm{I})$ form $[46,50]$. Once in its active form, an LPMO can catalyze a number of oxidative cleavages until the active site copper happens to be re-oxidized, either by $\mathrm{H}_{2} \mathrm{O}_{2}$ or $\mathrm{O}_{2}$ [50]. The reductants that are required for LPMO activation are amenable to abiotic oxidation by $\mathrm{O}_{2}$ and $\mathrm{H}_{2} \mathrm{O}_{2}$ is often a product of these oxidations, complicating experimental assessment of LPMO action [51]. LPMOs are also a subject of irreversible inactivation by non-productive redox processes in the catalytic center $[46,48,49$, 51]. Therefore, the fine-tuned control over the concentration of the oxygen co-substrate is of utmost importance in harnessing the full catalytic potential of LPMOs.

Here, we have studied to what extend liquid fractions (LFs) from hydrothermal pre-treatment of wheat straw support the degradation of cellulose by a Trichoderma reesei LPMO (TrLPMO9A) as well as the degradation of chitin by a Serratia marcescens LPMO (SmLPMO10A). Reducing power and LPMO-independent generation of $\mathrm{H}_{2} \mathrm{O}_{2}$ in such liquid fractions were found to drive the LPMO activity, shedding new light on the possible interplay between biomass pretreatment and subsequent saccharification by LPMO-containing enzyme cocktails.

\section{Methods}

\section{Substrates and reagents}

${ }^{14} \mathrm{C}$-labeled chitin nanowhiskers (CNWs) were prepared by $\mathrm{N}$-acetylation of non-labeled $\mathrm{CNWs}$ with ${ }^{14} \mathrm{C}$-acetic anhydride exactly as described in Kuusk et al. [52]. ${ }^{14} \mathrm{C}$-labeled bacterial cellulose was prepared by laboratory fermentation of Gluconobacter xylinum (ATCC 53582) in a medium supplied with uniformly ${ }^{14} \mathrm{C}$-labeled glucose as described before [53, 54]. ${ }^{14} \mathrm{C}$-labeled microcrystalline cellulose (BMCC) was prepared by incubating ${ }^{14} \mathrm{C}$-labeled bacterial cellulose $\left(2 \mathrm{~g} \mathrm{~L}^{-1}\right)$ with $1.0-\mathrm{M}$ $\mathrm{HCl}$ at $100{ }^{\circ} \mathrm{C}$ for $3 \mathrm{~h}$ followed by extensive washing with water. The specific radioactivities of CNWs and BMCC were $4.18 \times 10^{6}$ and $6.4 \times 10^{5} \mathrm{dpm} \mathrm{mg}^{-1}$, respectively. Before using in experiments, both CNWs and BMCC were treated with EDTA to remove divalent metal ions. For that the polysaccharide $\left(2 \mathrm{~g} \mathrm{~L}^{-1}\right)$ was incubated with 10-mM EDTA at room temperature overnight. The EDTA-treated polysaccharides were extensively washed with water and 50-mM sodium acetate ( $\mathrm{pH}$ 5.0) through repetitive centrifugation and re-suspension steps. The water was Milli-Q ultrapure water that had been passed through a column with Chelex ${ }^{\circledR} 100$ resin (BioRad). The stock solution of sodium acetate buffer was stored over beads of Chelex ${ }^{\circledR} 100$ resin. Solutions of $\mathrm{H}_{2} \mathrm{O}_{2}$ and ascorbic acid were made freshly before use.

\section{Enzymes}

$S m L P M O 10 A$ was produced and purified as described before [55]. TrLPMO9A was produced as follows: the gene encoding TrLPMO9A was obtained by PCR from genomic DNA of T. reesei QM9414 using oligonucleotides SO1 (5'AACCCAATAGTCAACCGCGGACTG CGCATCATGATCCAGAAGCTTTCCAA) and SO2 (5'ACCGGTGCGTCAGGCTTTCGCCACGGAGCT CTAGTTAAGGCACTGGGCGT). The expression vector was assembled with the yeast recombination cloning method using the PCR fragment and PacI (Fermentas) linearized pTTv248 vector backbone [56]. The final expression vector contained a targeting sequence for the cbh1 locus (tre123989), 2184 bp of $c b h 15^{\prime}$ region containing the $c b h 1$ promoter and $1745 \mathrm{bp}$ of $c b h 13^{\prime}$ region and the hphR selection marker $[57,58]$. After plasmid rescue and transformation into E. coli [56], the construct was verified by sequencing. The expression cassette was liberated from the vector backbone with PmeI (Fermentas) 
restriction enzyme digestion prior to transformation. $T$. reesei strain M362 (M124 $\Delta$ tre72567, $\Delta$ tre122081 and $\Delta$ tre120312), which is deleted for three major cellulase genes (cbh2, egl1, egl2), was transformed with the expression cassette and grown on MM+hygromycin transformation plates [59]. Transformants were screened first by PCR for $5^{\prime}$ and $3^{\prime}$ flank integration into the $c b h 1$ locus and absence of the open reading frame for $c b h 1$ (for PCR primers see Additional file 1: Table S1). The generated strain, M1906, was cultivated for protein production in a BioFlo 510 15L reactor (New Brunswick Scientific, USA) with 10-L operating volume, using a culture medium containing lactose $\left(40 \mathrm{~g} \mathrm{~L}^{-1}\right)$, spent grain extract $\left(30 \mathrm{~g} \mathrm{~L}^{-1}\right)$ (Harbro Ltd, UK), $\mathrm{KH}_{2} \mathrm{PO}_{4}\left(5 \mathrm{~g} \mathrm{~L}^{-1}\right),\left(\mathrm{NH}_{4}\right)_{2} \mathrm{SO}_{4}\left(5 \mathrm{~g} \mathrm{~L}^{-1}\right)$ $\mathrm{MgSO}_{4}(2.4 \mathrm{mM}), \mathrm{CaCl}_{2}(4.1 \mathrm{mM}), \mathrm{CoCI}_{2}\left(3.7 \mathrm{mg} \mathrm{L}^{-1}\right)$, $\mathrm{FeSO}_{4} \cdot 7 \mathrm{H}_{2} \mathrm{O}\left(5 \mathrm{mg} \mathrm{L}^{-1}\right), \mathrm{ZnSO}_{4} \cdot 7 \mathrm{H}_{2} \mathrm{O}\left(1.4 \mathrm{mg} \mathrm{L}^{-1}\right)$ and $\mathrm{MnSO}_{4} \cdot 7 \mathrm{H}_{2} \mathrm{O}\left(1.6 \mathrm{mg} \mathrm{L}^{-1}\right)$ and Struktol J647 Antifoam $\left(1 \mathrm{~mL} \mathrm{~L}^{-1}\right)$. The cultivation was carried out at $28^{\circ} \mathrm{C}$ and $\mathrm{pH}$ 4.8-4.9. The $\mathrm{pH}$ was controlled by addition of base $\left(5 \% \mathrm{NH}_{4} \mathrm{OH}\right)$ or acid $\left(10 \% \mathrm{H}_{3} \mathrm{PO}_{4}\right)$ when necessary. The cultivation was done with constant aeration $\left(10 \mathrm{~L} \mathrm{~min}^{-1}\right)$ and mixing (150-500 rpm) was adjusted to keep the oxygen concentration at $30 \%$. Lactose $(20 \%(\mathrm{w} / \mathrm{v}))$ feeding was initiated after 61 -h cultivation and adjusted as described in [60]. The cultivation was terminated after $163 \mathrm{~h}$. The culture supernatant was concentrated with Millipore Pellicon 2 filter (10 kDa membrane cutoff). TrLPMO9A was purified with the following procedure: $0.5 \mathrm{~L}$ of the concentrated culture supernatant was exchanged to $10-\mathrm{mM}$ sodium phosphate $\mathrm{pH} 7.0$ using a Sephadex G25 column (column volume 3.5 L), applied to a DEAE Sepharose anion exchange column (column volume $1.0 \mathrm{~L}$ ) and eluted using a $0-100 \mathrm{mM}$ (30 column volumes) $\mathrm{NaCl}$ gradient. The fractions were analyzed with SDS-PAGE using 4-20\% Stain-Free gradient gels and Imaging System (BioRad, Hercules, California, USA). The fractions containing TrLPMO9A were pooled and buffer was exchanged to $50 \mathrm{mM}$ sodium acetate $\mathrm{pH} 5$ using ultrafiltration (Prep/Scale-TFF $1 \mathrm{ft}^{2}$ Cartridge, PTGC $10 \mathrm{k}$ Polyethersulfone). Ammonium sulfate was added to the pooled sample to a final concentration $0.5 \mathrm{M}$ after which the sample was applied to a Phenyl-Sepharose HIC column (column volume 0.14 L). TrLPMO9A was collected from the flow-through. The buffer of purified TrLPMO9A was changed to $25-\mathrm{mM}$ sodium acetate $\mathrm{pH} 5.0$ and the enzyme was concentrated using ultrafiltration as described above. SDS-PAGE analysis of purified TrLPMO9A is shown in the Additional file 1: Fig. S1. Contaminating endoglucanase [61], xylanase [62] and mannanase trace activities [63] of purified $\operatorname{Tr}$ LPMO9A were 1.2, 3.2, and $2.6 \mathrm{nkat} \mathrm{mg}^{-1}$ protein, respectively.

The purified LPMOs (around $150 \mu \mathrm{M}$ ) were copper saturated by overnight incubation with $\mathrm{CuSO}_{4}$ (threefold molar excess) and subsequent removal of free copper by ultrafiltration. The concentration of LPMOs was determined by measuring absorbance at $280 \mathrm{~nm}$ using molar extinction coefficients of 35,200 and $54,360 \mathrm{M}^{-1} \mathrm{~cm}^{-1}$ for SmLPMO10A and TrLPMO9A, respectively. Horseradish peroxidase (HRP, Sigma) was used as purchased. The concentration of HRP was determined by measuring absorbance at $403 \mathrm{~nm}$ using molar extinction coefficient of $102,000 \mathrm{M}^{-1} \mathrm{~cm}^{-1}$.

\section{Hydrothermal pretreatment of wheat straw}

Chopped wheat straw from Finland was pre-soaked with water to $50 \%$ dry matter content and loaded into a $30-\mathrm{L}$ pressure reactor with a batch size of 1.71-kg dry matter. The material was heated to $195{ }^{\circ} \mathrm{C}$ with direct steam injection and a pressurized water jacket, and the temperature was maintained for $15 \mathrm{~min}$. After the treatment, the material was quickly cooled to $80{ }^{\circ} \mathrm{C}$ with the water jacket, and dissolved material was extracted by pumping $80{ }^{\circ} \mathrm{C}$ water through the material bed. The first $6 \mathrm{~L}$ of extract was collected and this material is hereafter referred to as liquid fraction (LF). The pretreated solids were collected manually. During the period of analysis (about 2 months) the LF was stored at $4{ }^{\circ} \mathrm{C}$. After that, the LF was stored frozen as aliquots of appropriate volume.

The LF was analyzed for soluble carbohydrates by HPAEC with pulse amperometric detection (Dionex ICS 3000 equipped with CarboPac PA1 column). Analysis was performed before and after acid hydrolysis $\left(3 \% \mathrm{H}_{2} \mathrm{SO}_{4}\right.$, $1 \mathrm{~h}$ at $120^{\circ} \mathrm{C}$ ), to determine both mono- and oligomeric sugars. Furfural, hydroxymethyl furfural and acetic acid were analyzed by HPLC, using a Bio-Rad Aminex HPX$87 \mathrm{H}$ column, with $5-\mathrm{mM} \mathrm{H}_{2} \mathrm{SO}_{4}$ as eluent. Soluble phenolics were determined by UV-absorbance at $215 \mathrm{~nm}$ and $280 \mathrm{~nm}$, according to the method for acid-soluble lignin determination described by Goldschmid [64].

Compositional analysis of the solids was performed according to Sluiter et al. [65]. The main components of the solid fraction were glucose (41.5\%), xylose (7.3\%), lignin (24.5\%), and ash (5.8\%). The solid fraction was kept frozen in plastic bags.

\section{Degradation of CNWs by SmLPMO10A}

Experiments were made in $50-\mathrm{mM}$ sodium acetate $\mathrm{pH}$ 5.0 at $25{ }^{\circ} \mathrm{C}$. Stirring was omitted but the reaction mixture was gently mixed with a pipet before each sampling. The concentration of CNWs was $1.0 \mathrm{~g} \mathrm{~L}^{-1}$ and the concentration of $S m L P M O 10$ A was varied between 0.05 and $0.25 \mu \mathrm{M}$. The $S m \mathrm{LPMO} 10 \mathrm{~A}$ was added to the CNWs followed by the addition of LF (pre-incubated at $25{ }^{\circ} \mathrm{C}$ for the indicated time) to start the reaction. The amount of added LF corresponded to $5 \%, 10 \%$ or $15 \%(\mathrm{v} / \mathrm{v})$ of the final reaction volume. At selected time 
points, $0.1-\mathrm{mL}$ aliquots were withdrawn and mixed with $0.025 \mathrm{~mL}$ of $1.0-\mathrm{M} \mathrm{NaOH}$ to stop the reaction. Non-labeled CNWs (to $3 \mathrm{~g} \mathrm{~L}^{-1}$ ) in $0.2-\mathrm{M} \mathrm{NaOH}$ were added to improve sedimentation [52] and solids were separated by centrifugation $\left(5 \min \times 10^{4} g\right)$. SmLPMO10A activity was calculated based on the concentration of radioactive soluble products (expressed in $\mathrm{N}$-acetylglucosamine equivalents, $\mathrm{NAG}_{\text {eq }}$ ) exactly as described in Kuusk et al. [48]. In this previous study, it was established that one $S m$ LPMO10A oxidative cleavage on average leads to release of approximately four $\mathrm{NAG}_{\mathrm{eq}}$ and this 4 to 1 ratio takes into account that part of the oxidized sites remains in the insoluble substrate [48]. Therefore, the concentration of $\mathrm{NAG}_{\mathrm{eq}}$ corresponds to the total concentration of monosaccharide equivalents in the soluble fraction and is not dependent on the average degree of polymerization of soluble products (which is known to be around 8 for the SmLPMO10A/CNWs system [48]). In the experiments with HRP, the LF (or solid fraction, see below) was mixed with CNWs. HRP (1.0- $\mu \mathrm{M}$ final concentration) was added to the mixture of CNWs and LF followed by the addition of SmLPMO10A (30 s after the addition of HRP) to start the reaction. In the control experiments without LF or SmLPMO10A, the experiments were made as described above but the LF or SmLPMO10A were replaced with corresponding amount of buffer.

In the experiments for measuring the concentration of $\mathrm{H}_{2} \mathrm{O}_{2}$ in LF upon pre-incubation of LF at $50{ }^{\circ} \mathrm{C}$, the aliquot of pre-incubated LF (to a final concentration of $10 \% \mathrm{v} / \mathrm{v}$ ) was added to the mixture of CNWs and $S m L P M O 10 A$ to start the reaction. The SmLPMO10A reaction was conducted at $25{ }^{\circ} \mathrm{C}$ as described above. In some cases, ascorbic acid (0.1-mM final concentration) was added ( $30 \mathrm{~s}$ before the addition of LF) to ensure efficient priming of SmLPMO10A [50]. The concentration of $\mathrm{H}_{2} \mathrm{O}_{2}$ was calculated from the concentration of soluble $\mathrm{NAG}_{\text {eq }}$ using a previously established stoichiometry of 4 $\mathrm{NAG}_{\mathrm{eq}} / \mathrm{H}_{2} \mathrm{O}_{2}$ [48].

In the experiments with the solid fraction from the hydrothermal pretreatment of wheat straw, $40-\mathrm{mL}$ water (at $4{ }^{\circ} \mathrm{C}$ ) was added to $5 \mathrm{~g}$ of frozen solid fraction. After $30 \mathrm{~min}$, the solids were separated by centrifugation and the pellet was homogenized by grinding in a mortar (at $4{ }^{\circ} \mathrm{C}$ ) until it was possible to handle the suspension with a pipet. The concentration of solids in homogenized material was measured by weighing (after drying in a rotary evaporator). The experiments with the solid fraction (10 $\mathrm{g} \mathrm{L}^{-1}$ solids were added to SmLPMO10A reaction) were made exactly as described above for the experiments with LF.

In all cases, the sample for the zero-time point was withdrawn before the addition of LF and was treated as the other samples. The reading of the zero-time point was subtracted from the readings of all time points.

\section{Degradation of BMCC by TrLPMO9A}

Experiments were made in $50-\mathrm{mM}$ sodium acetate $\mathrm{pH}$ 5.0 at $25{ }^{\circ} \mathrm{C}$ or $50{ }^{\circ} \mathrm{C}$ in $1.0-\mathrm{mL}$ total volume. Stirring was omitted but the reaction mixture was gently mixed with a pipet before each sampling. The concentration of BMCC was $0.6 \mathrm{~g} \mathrm{~L}^{-1}$ or $1.2 \mathrm{~g} \mathrm{~L}^{-1}$ and that of TrLPMO9A was varied between 0.1 and $0.5 \mu \mathrm{M}$. The LF (preincubated at $25{ }^{\circ} \mathrm{C}$ or $50{ }^{\circ} \mathrm{C}$ for the indicated time) was added to the BMCC and the reaction was started by the addition of TrLPMO9A. The amount of added LF corresponded to $10 \%$ or $20 \%(\mathrm{v} / \mathrm{v})$ of the total reaction volume. At selected time points, $0.2-\mathrm{mL}$ aliquots were withdrawn and the solids were immediately separated by centrifugation $\left(2 \mathrm{~min} \times 10^{4} g\right)$. Of note, the stopping by alkali was not suitable because of high and nonstable background readings of the LF BMCC mixtures in the alkaline conditions. The concentration of soluble products (expressed in $\mathrm{Glc}_{\mathrm{eq}}$ ) was calculated from the radioactivity readings in the supernatants. For this, the radioactivity readings in the supernatant were first converted into the degree of conversion of BMCC (using total radioactivity of BMCC in the sample) and the degree of conversion of BMCC was converted into the concentration of glucose equivalents (using total glucose in BMCC). In the experiments with HRP, the HRP (1.0- $\mu \mathrm{M}$ final concentration) was added to the mixture of BMCC and LF 1 min before starting the reaction by the addition of TrLPMO9A. In the control experiments without LF or TrLPMO9A, the experiments were made as described above but the LF or TrLPMO9A was replaced with corresponding amounts of buffer. In the experiments where reactions were supplied with $\mathrm{H}_{2} \mathrm{O}_{2}$, the $\mathrm{H}_{2} \mathrm{O}_{2}$ (10-50- $\mu \mathrm{M}$ final concentration) was added to the mixture of BMCC and LF immediately before starting the reaction by adding $\operatorname{Tr}$ LPMO9A.

In all cases, a sample for the zero-time point was withdrawn just before the addition of TrLPMO9A and was treated as the other samples. The reading of the zerotime point was subtracted from the readings of all time points.

\section{Pre-incubation of LF before LPMO reaction}

The $1.0-\mathrm{mL}$ frozen aliquots of LF in $2.0-\mathrm{mL}$ screw-cap vials were placed in a thermostat bath and incubated at $25{ }^{\circ} \mathrm{C}$ or $50{ }^{\circ} \mathrm{C}$ for durations ranging from 0.5 to $96 \mathrm{~h}$. Time after time the vials were gently mixed by turning around and the caps were opened (at least once in a day) to allow equilibration with fresh air. Incubation was made in the dark without stirring. The zero time for pre-incubation is the time when the vial with frozen LF was placed (it took few min to melt the material) in 
the thermostat bath. A small amount of solids in the LF precipitated by gravity and these were not added to the LPMO reactions. After defined pre-incubation times, the LF was added to the LPMO reactions as detailed above.

\section{Results}

The liquid fraction from hydrothermal pretreatment of wheat straw supports activity of a chitin-active LPMO

The kinetics of $\mathrm{H}_{2} \mathrm{O}_{2}$-driven degradation of chitin $\left({ }^{14} \mathrm{C}\right.$-labeled crystalline $\alpha$-chitin nanowhiskers, $\left.\mathrm{CNWs}\right)$ by $S m L P M O 10 A$ has been characterized in detail before [48, 50]. Provided with $0.1-\mathrm{mM}$ AscA as reductant, the $k_{\text {cat }}$ value for oxidation of CNWs was 6.7 oxidative cleavages $\mathrm{s}^{-1}$ and the $K_{\mathrm{m}}$ values for $\mathrm{H}_{2} \mathrm{O}_{2}$ and CNWs are $2.8 \mu \mathrm{M}$ and $0.58 \mathrm{~g} \mathrm{~L}^{-1}$, respectively. One molecule of $\mathrm{H}_{2} \mathrm{O}_{2}$ supports one oxidative cleavage with concomitant release of 4 soluble $N$-acetylglucosamine equivalents $\left(\mathrm{NAG}_{\mathrm{eq}}\right)$ [48]. Different reducing agents like ascorbic acid, gallic acid and methylhydroquinone can support $\mathrm{H}_{2} \mathrm{O}_{2}$-driven oxidation of CNWs by SmLPMO10A [50]. Here, we show that the liquid fraction (LF) from hydrothermal pretreatment of wheat straw (for the composition see Table 1) can also support oxidation of CNWs by SmLPMO10A. Addition of LF to the premixed CNWs and SmLPMO10A resulted in the release of ${ }^{14} \mathrm{C}$-labeled soluble products (expressed in $\mathrm{NAG}_{\text {eq }}$, Fig. 1a). There was no activity in the control experiments without SmLPMO10A or LF. In line with earlier observations $[46,50]$, the release of $\mathrm{NAG}_{\text {eq }}$ were not detected in the presence of horseradish peroxidase (HRP) indicating that the $\mathrm{H}_{2} \mathrm{O}_{2}$ is responsible for the activity of $S m L P M O 10$ A under the conditions used. Since no external electron donor (reductant) nor $\mathrm{H}_{2} \mathrm{O}_{2}$ was added, these results suggest that compounds present in LF support $S m L P M O 10 A$ with both, electrons and the $\mathrm{H}_{2} \mathrm{O}_{2}$ co-substrate.

Time curves of $\mathrm{NAG}_{\mathrm{eq}}$ formation were in accordance with the so-called "burst" kinetics, which is characterized

Table 1 Main components of the liquid fraction from hydrothermal pre-treatment of wheat straw

\begin{tabular}{|c|c|}
\hline Compound $^{a}$ & $\begin{array}{l}\text { Concentration } \\
\left(g \mathrm{~L}^{-1}\right)\end{array}$ \\
\hline Xylose total ${ }^{b}$ & 4.28 \\
\hline Xylose monomeric & 0.37 \\
\hline Acetate & 1.4 \\
\hline Hydroxymethyl furfural & $<0.004$ \\
\hline Furfural & 0.46 \\
\hline UV-phenolics & 2.04 \\
\hline
\end{tabular}

a $\mathrm{LF}$ also contained low amounts of glucose (total $0.53 \mathrm{~g} \mathrm{~L}^{-1}$ ), arabinose (total $0.34 \mathrm{~g} \mathrm{~L}^{-1}$ ), fructose (total $0.27 \mathrm{~g} \mathrm{~L}^{-1}$ ), and galactose (total $0.26 \mathrm{~g} \mathrm{~L}^{-1}$ )

b The total amount of sugars was measured after acid hydrolysis of $\mathrm{LF}$

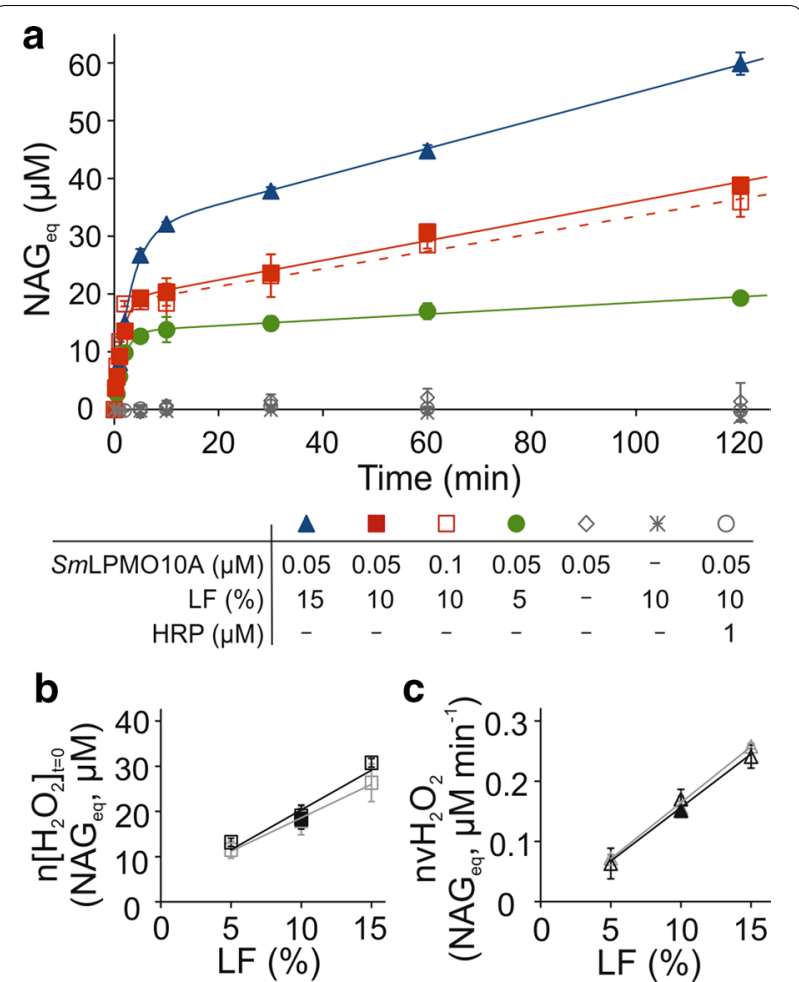

Fig. 1 Liquid fraction (LF) supports the degradation of chitin by $\mathrm{SmLPMO10A}$. Reactions were made in $50 \mathrm{mM}$ sodium acetate $\mathrm{pH}$ 5.0) at $25^{\circ} \mathrm{C}$. The concentration of CNWs was $1.0 \mathrm{~g} \mathrm{~L}^{-1}$ and that of $\mathrm{SmLPMO10A}$ was $0.05 \mu \mathrm{M}$ (except in one series where it was $0.1 \mu \mathrm{M}$, as indicated in the Figure). Before use in the reactions, the LF was pre-incubated at $25^{\circ} \mathrm{C}$ for overnight. The amount of LF was $5 \%, 10 \%$, or $15 \%$ of the total reaction volume. a Time curves of the formation of soluble products (expressed in $\mathrm{N}$-acetylglucosamine equivalents, $N A G_{\text {eq }}$ ) upon incubation of CNWs with SmLPMO10A in the presence of LF. Solid lines show the best-fit of non-linear regression analysis according to Eq. 1. Control experiments show the results obtained (i) with $10 \% \mathrm{LF}$ but in the presence of $1-\mu \mathrm{M}$ horseradish peroxidase (note that no extra HRP substrate was added, since the LF contains HRP substrates), (ii) with 10\% LF but in the absence of SmLPMO10A, or (iii) in the absence of LF. Note that no reductant was added to these reaction mixtures. $\mathbf{b}, \mathbf{c}$ Dependence of $(\mathbf{b}) n\left[\mathrm{H}_{2} \mathrm{O}_{2}\right]_{t=0}$, and (c) $n \mathrm{~V}_{2} \mathrm{O}_{2}$ on the concentration of $L F$ in the LPMO reaction. The values of $n\left[\mathrm{H}_{2} \mathrm{O}_{2}\right]_{t=0}$ and $n v_{\mathrm{H}_{2}} \mathrm{O}_{2}$ were found by analysis of the data in $\mathbf{a}$ using non-linear regression analysis according to Eq. 1 (opened black symbols) or linear regression analysis (only the data points measured between 10 and 120 min were included here) according Eq. 2 (open gray symbols). Filled black symbols represents the data obtained with $10 \% \mathrm{LF}$ and double the amount $(0.1 \mu \mathrm{M})$ of $\mathrm{SmLPMO10A}$. Error bars represent S.D. and are from at least two independent measurements

by an initial transient burst of activity followed by slow and linear formation of $\mathrm{NAG}_{\mathrm{eq}}$ in time (Fig. 1a). Under our experimental conditions, the initial burst decayed within the first $10 \mathrm{~min}$; whereas, the linear formation of products in time continued up to the longest time point tested $(2 \mathrm{~h})$. One may speculate that the initial activity burst is due to rapid consumption of $\mathrm{H}_{2} \mathrm{O}_{2}$ already 
present in LF at time zero (i.e., before the addition of LPMO); whereas the linear stage reflects the slow formation of $\mathrm{H}_{2} \mathrm{O}_{2}$ in the reaction mixture (see below). Notably, doubling the concentration of SmLPMO10A (from $0.05 \mu \mathrm{M}$ to $0.1 \mu \mathrm{M}$ ) had no effect on the rate of $\mathrm{NAG}_{\mathrm{eq}}$ formation in linear stage. This suggests that $\mathrm{H}_{2} \mathrm{O}_{2}$ is forming in a reaction independent from the LPMO. In the case of low initial $\mathrm{H}_{2} \mathrm{O}_{2}$ concentrations (i.e., conditions where enzyme inactivation can be ignored) [48], Eq. 1 can be used as a first approximation to describe the system.

$$
\left[\mathrm{NAG}_{\mathrm{eq}}\right]=n\left[\mathrm{H}_{2} \mathrm{O}_{2}\right]_{(t=0)}\left(1-\mathrm{e}^{-k_{(\mathrm{LPMO})}^{\mathrm{obs}} t}\right)+n v_{\left(\mathrm{H}_{2} \mathrm{O}_{2}\right)} t
$$

In Eq. 1, the $n$ is an average number of soluble sugars (in monosaccharide equivalents) released per one molecule of $\mathrm{H}_{2} \mathrm{O}_{2}$ consumed by LPMO (for SmLPMO10A with CNWs, $n=4),\left[\mathrm{H}_{2} \mathrm{O}_{2}\right]_{(t=0)}$ is the initial concentration of $\mathrm{H}_{2} \mathrm{O}_{2}$ in the LF, and $t$ is time. The $k_{(\mathrm{LPMO})}^{\text {obs }}$ is the observed rate constant of LPMO-catalyzed oxidation of polysaccharide. $k_{(\mathrm{LPMO})}^{\text {obs }}$ depends not only on the values of kinetic parameters, the concentrations of polysaccharide and LPMO [48] but also on the nature and concentration of the reductant [50]. The $v_{\left(\mathrm{H}_{2} \mathrm{O}_{2}\right)}$ is the rate of LPMO-independent formation of $\mathrm{H}_{2} \mathrm{O}_{2}$ in LF. Note that with Eq. 1 we assume that the rate of $\mathrm{H}_{2} \mathrm{O}_{2}$ consumption in polysaccharide oxidation by LPMO is much higher than the rate of its formation/decomposition in LF, so that the $v_{\left(\mathrm{H}_{2} \mathrm{O}_{2}\right)}$ is directly reflected in the formation of LPMO products $\left(\mathrm{NAG}_{\mathrm{eq}}\right.$ ). This assumption is plausible since doubling the concentration of SmLPMO10A had no effect on the steady-state rate of the LPMO reaction (Fig. 1a).

The time curves of the release of $\mathrm{NAG}_{\text {eq }}$ made at different LF concentrations were in accordance with Eq. 1 (Fig. 1a, solid lines). Nonlinear regression analysis was used to find the values of parameters and there was a linear correlation between the concentration of LF and both, $n\left[\mathrm{H}_{2} \mathrm{O}_{2}\right]_{(t=0)}$ and $n v_{\left(\mathrm{H}_{2} \mathrm{O}_{2}\right)}$ (Fig. 1b, c). On the other hand both, $n\left[\mathrm{H}_{2} \mathrm{O}_{2}\right]_{(t=0)}$ and $n v_{\left(\mathrm{H}_{2} \mathrm{O}_{2}\right)}$ were independent of the concentration of SmLPMO10A. These results are in accordance with the model whereby the kinetics of LFdriven degradation of CNWs by $S m L P M O 10 A$ is governed by the $\mathrm{H}_{2} \mathrm{O}_{2}$ initially present in LF and that formed in LF, in an LF-dependent but SmLPMO10A-independent manner.

\section{$\mathrm{H}_{2} \mathrm{O}_{2}$ is formed in LF but does not accumulate to high levels upon incubation of $L F$ in aerobic conditions}

Sensitive detection of $\mathrm{H}_{2} \mathrm{O}_{2}$ above a background in a redox-active environment such as LF, with a myriad of compounds and ongoing reactions, is a challenging task. Therefore, we exploited the dependency of the kinetics of the SmLPMO10A/CNW system on available $\mathrm{H}_{2} \mathrm{O}_{2}$ and used the kinetics of LPMO catalysis with a ${ }^{14} \mathrm{C}$-labeled polymeric substrate for sensing, not only the concentration but also the rate of the formation of $\mathrm{H}_{2} \mathrm{O}_{2}$ in the LF. First, we were interested in if and how $\left[\mathrm{H}_{2} \mathrm{O}_{2}\right]_{(t=0)}$ and $v_{\left(\mathrm{H}_{2} \mathrm{O}_{2}\right)}$ change upon incubation of LF in aerobic conditions. For that, we pre-incubated $\mathrm{LF}$ at $25{ }^{\circ} \mathrm{C}$ in the dark without stirring for time-periods ranging from 0.5 to $96 \mathrm{~h}$. Zero time for pre-incubation is the time when the frozen vial with LF was placed at $25^{\circ} \mathrm{C}$. After preincubation, an aliquot of LF was added $(10 \% \mathrm{v} / \mathrm{v})$ to the mixture of CNWs and SmLPMO10A, and the formation of $\mathrm{NAG}_{\text {eq }}$ in time was followed, which was then used to calculate $\left[\mathrm{H}_{2} \mathrm{O}_{2}\right]_{(t=0)}$ and $v_{\left(\mathrm{H}_{2} \mathrm{O}_{2}\right)}$. Here, only the linear regions of $\mathrm{NAG}_{\mathrm{eq}}$ formation in time were assessed (from $10 \mathrm{~min}$ to $2 \mathrm{~h}$ ). The $k_{(\mathrm{LPMO})}^{\mathrm{obs}}$ values found from the analysis of the data in Fig. 1a were in the order of $0.6 \mathrm{~min}^{-1}$. This translates to the half-life of $\left[\mathrm{H}_{2} \mathrm{O}_{2}\right]_{(t=0)}$ in the LPMO reaction of around $1 \mathrm{~min}$. After $10 \mathrm{~min}$ of $S m \mathrm{LPMO} 10 \mathrm{~A}$ reaction, the exponential term is close to zero (as visible in Fig. 1a) and Eq. 1 simplifies to:

$$
\left[\mathrm{NAG}_{\mathrm{eq}}\right]=n\left[\mathrm{H}_{2} \mathrm{O}_{2}\right]_{(t=0)}+n v_{\left(\mathrm{H}_{2} \mathrm{O}_{2}\right)} t
$$

Provided that $n$ and $v_{\left(\mathrm{H}_{2} \mathrm{O}_{2}\right)}$ is time invariant, Eq. 2 can be analyzed using linear regression. This simplified approach is justified, as the $n\left[\mathrm{H}_{2} \mathrm{O}_{2}\right]_{(t=0)}$ and $n v_{\left(\mathrm{H}_{2} \mathrm{O}_{2}\right)}$ values found using full progress curves and analysis according to Eq. 1 were very similar to the values found when using Eq. 2 (Fig. 1b, c).

Figure 2a shows time curves for $\mathrm{NAG}_{\mathrm{eq}}$ formation over time in reactions with LF subjected to varying periods of pre-incubation. For each time of LF preincubation, the time curves of $\mathrm{NAG}_{\mathrm{eq}}$ formation were measured using three different (each in single parallel) SmLPMO10A concentrations $(0.05,0.1$, and $0.25 \mu \mathrm{M})$. Since no clear dependence on LPMO concentration was found (Additional file 1: Fig. S2), average results obtained with different enzyme concentrations are shown in Fig. 2a. The increase in $\left[\mathrm{NAG}_{\mathrm{eq}}\right]$ was linear in time regardless of the pre-incubation time of LF. However, the intercept increased, while the slope slightly decreased with increasing pre-incubation time. Next we converted the values of intercepts to the values of $\left[\mathrm{H}_{2} \mathrm{O}_{2}\right]_{(t=0)}$ and the values of slopes to the values of $v_{\left(\mathrm{H}_{2} \mathrm{O}_{2}\right)}$ using the known stoichiometry of $\operatorname{SmLPMO} 10 \mathrm{~A}$ reaction $\left(n=4\right.$; so $4 \mathrm{NAG}_{\mathrm{eq}}$ are produced per $\left.\mathrm{H}_{2} \mathrm{O}_{2}\right)$. The dependence of $\left[\mathrm{H}_{2} \mathrm{O}_{2}\right]_{(t=0)}$ and $v_{\left(\mathrm{H}_{2} \mathrm{O}_{2}\right)}$ on pre-incubation time is shown in Fig. 2b and c, respectively. The rate of $\mathrm{H}_{2} \mathrm{O}_{2}$ formation in LF slightly decreased with the pre-incubation time of LF and was in the order of 1.0-1.5 $\mu \mathrm{M} \mathrm{h}^{-1}$ (Fig. 2c). The concentration of $\mathrm{H}_{2} \mathrm{O}_{2}$ in LF increased upon pre-incubation of LF but seemed to level off around 3-5 $\mu \mathrm{M}$ in 


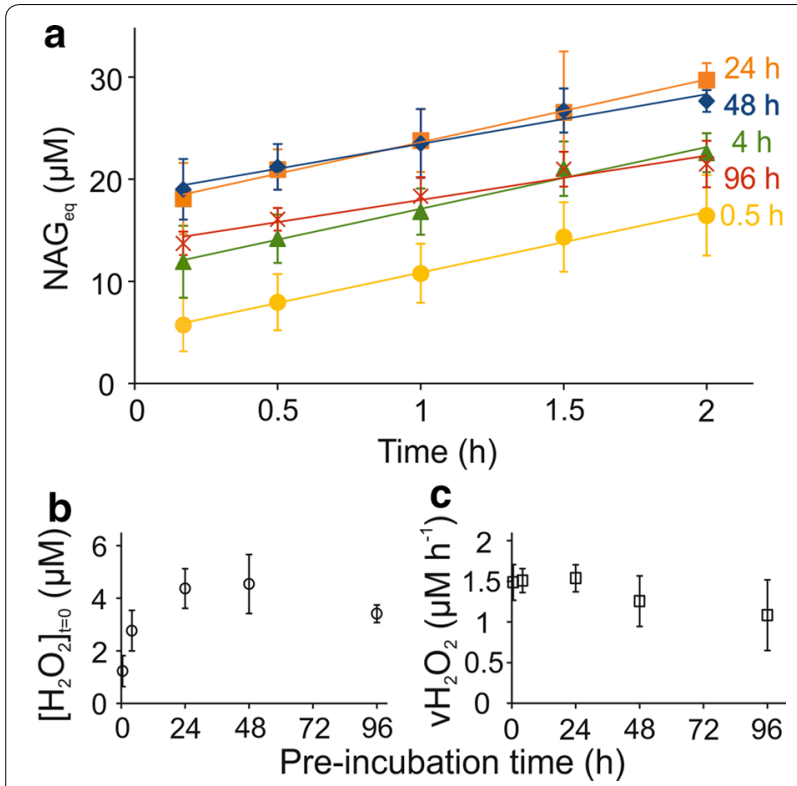

Fig. 2 Dependence of the $\left[\mathrm{H}_{2} \mathrm{O}_{2}\right]_{t=0}$ and $v_{\left(\mathrm{H}_{2} \mathrm{O}_{2}\right)}$ on pre-incubation time of LF at $25^{\circ} \mathrm{C}$. Reactions were made in $50 \mathrm{mM}$ sodium acetate (pH 5.0) at $25^{\circ} \mathrm{C}$. The concentration of CNWs was $1.0 \mathrm{~g} \mathrm{~L}^{-1}$ and that of $L F$ was $10 \%(\mathrm{~V} / \mathrm{V})$. a Time curves of the formation of soluble products (expressed in $\mathrm{N}$-acetylglucosamine equivalents, $N A G_{e q}$ ) upon incubation of CNWs with SmLPMO10A in the presence of LF that was pre-incubated at $25^{\circ} \mathrm{C}$ for different times (as indicated in the plot). The graphs shows average values, and S.D, obtained from experiments with $S \mathrm{mLPMO} 10 \mathrm{~A}$ concentrations of $0.05 \mu \mathrm{M}$, $0.1 \mu \mathrm{M}$, or $0.25 \mu \mathrm{M}$ (see Additional file 1: Fig. S2 for the individual curves). Solid lines show linear regression of the data according to Eq. 2. b, c Dependence of (b) the $\left[\mathrm{H}_{2} \mathrm{O}_{2}\right]_{t=0}$ and $(\mathbf{c})$ the $v_{\left(\mathrm{H}_{2} \mathrm{O}_{2}\right)}$, on pre-incubation time of $L F$. The values of $\left[\mathrm{H}_{2} \mathrm{O}_{2}\right]_{t=0}$ and $v_{\left(\mathrm{H}_{2} \mathrm{O}_{2}\right)}$ were calculated from the parameter values of linear regression analysis of the data in $\mathbf{a}$ according to Eq. 2 using the stoichiometry ( $n$ ) of $4 \mathrm{NAG}_{\mathrm{eq}} / \mathrm{H}_{2} \mathrm{O}_{2}$ for the $\mathrm{SmLPMO} 10 \mathrm{~A} / \mathrm{CNW}$ s system [48]. Error bars represent S.D. and are from three independent measurements each made in single parallel but at different concentration of $5 m L P M O 10 A$ (Additional file 1: Fig. S2)

longer pre-incubations (Fig. 2b). Importantly, the levels of $\mathrm{H}_{2} \mathrm{O}_{2}$ in LF were much lower than those expected based on the rate of its formation. As an example, with a rate around $10 \mu \mathrm{M} \mathrm{h}^{-1}$ (note that we here extrapolate the rate of $\mathrm{H}_{2} \mathrm{O}_{2}$ formation measured in $10 \%$ LF to what is expected in case of $100 \% \mathrm{LF}$, assuming a linear correlation between $v_{\left(\mathrm{H}_{2} \mathrm{O}_{2}\right)}$ and [LF]), about 1.0- $\mathrm{mM} \mathrm{H}_{2} \mathrm{O}_{2}$ would be formed upon pre-incubation of LF for $96 \mathrm{~h}$. However, the measured $\left[\mathrm{H}_{2} \mathrm{O}_{2}\right]_{(t=0)}$ after 96-h pre-incubation was just $34 \pm 3 \mu \mathrm{M}$ (measured using $10 \% \mathrm{LF}$, but extrapolated to $100 \%$ LF assuming a linear correlation between $\left[\mathrm{H}_{2} \mathrm{O}_{2}\right]_{\left(\mathrm{H}_{2} \mathrm{O}_{2}\right)}$ and [LF]). These results suggest that $\mathrm{H}_{2} \mathrm{O}_{2}$ is an intermediate of LF oxidation.

Of note, the solid fraction from hydrothermal pretreatment of wheat straw also supported SmLPMO10A

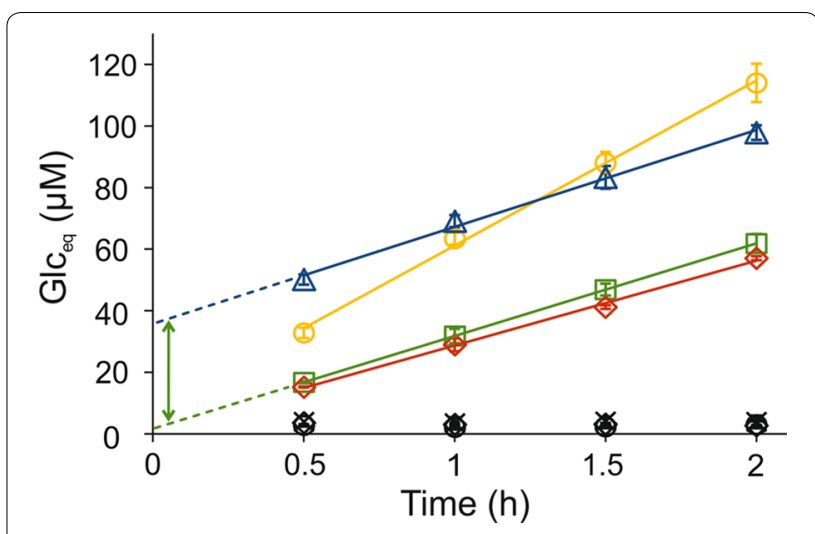

Fig. 3 Liquid fraction (LF) supports the degradation of cellulose (BMCC) by TrLPMO9A. Reactions were made in $50 \mathrm{mM}$ sodium acetate $(\mathrm{pH} 5.0)$ at $50{ }^{\circ} \mathrm{C}$. The concentration of BMCC was $0.6 \mathrm{~g} \mathrm{~L}^{-1}$ (except in one series where it was $1.2 \mathrm{~g} \mathrm{~L}^{-1}$, red diamonds). Before use in the LPMO reaction, the LF was pre-incubated at $50^{\circ} \mathrm{C}$ for $0.5 \mathrm{~h}$. All colored points and lines refer to reactions with LF with a concentration $10 \%$, except for the yellow series where it was $20 \%$ $(\mathrm{v} / \mathrm{v})$. In summary: green squares, base case; red diamonds, double BMCC concentration; yellow circles, double LF. The blue triangles are from an experiment where the concentration of LF was $10 \%$ but the reactions were supplied with $20-\mu \mathrm{M} \mathrm{H}_{2} \mathrm{O}_{2}$ at $t=0$. The green arrow shows the increase in intercept upon supplementation of the reaction with $20-\mu \mathrm{M} \mathrm{H}_{2} \mathrm{O}_{2}$. The graphs shows the average values, and S.D, obtained from experiments with TrLPMO9A concentrations (each in single parallel) of $0.1 \mu \mathrm{M}, 0.2 \mu \mathrm{M}$, or $0.5 \mu \mathrm{M}$ (see Additional file 1: Fig. 55 for the individual curves). The data points show the formation of soluble products (expressed in glucose equivalents, $\mathrm{Gl}_{\mathrm{eq}}$ ). Solid lines show linear regression of the data according to Eq. 2. Control experiments show the results obtained (i) with $10 \% \mathrm{LF}$ but in the presence of $1 \mu \mathrm{M} \mathrm{HRP}$ (black circles), (ii) with 10\% LF but in the absence of TrLPMO9A (black diamonds), or (iii) in the absence of LF (black crosses)

activity. An experiment with $10 \mathrm{~g} \mathrm{~L}^{-1}$ solid fraction at $25{ }^{\circ} \mathrm{C}, \mathrm{pH} 5.0$ (Additional file 1: Fig. S3) yielded an estimated $\mathrm{H}_{2} \mathrm{O}_{2}$ production rate of $1.4 \mu \mathrm{M} \mathrm{h}^{-1}$.

\section{LF from hydrothermal pretreatment of wheat straw supports activity of a cellulose-active LPMO}

Since LPMOs are important components of commercial cellulolytic cocktails, we were interested in whether the LF can support LPMOs also at $50{ }^{\circ} \mathrm{C}$, a more relevant temperature for industrial applications. Unfortunately, the use of $50{ }^{\circ} \mathrm{C}$ was not compatible with SmLPMO10A. Therefore, we used a cellulose-active LPMO of Trichoderma reesei (TrLPMO9A, formerly $\operatorname{TrCel61\mathrm {A})}[17,66-$ 69] and ${ }^{14} \mathrm{C}$-labeled bacterial microcrystalline cellulose (BMCC), to measure the $\left[\mathrm{H}_{2} \mathrm{O}_{2}\right]_{(t=0)}$ and $v_{\left(\mathrm{H}_{2} \mathrm{O}_{2}\right)}$ at $50{ }^{\circ} \mathrm{C}$. The LF indeed supported TrLPMO9A in releasing soluble products, the concentration of which was expressed in glucose equivalents $\left(\mathrm{Glc}_{\mathrm{eq}}\right.$ ), from $\mathrm{BMCC}$ at $50{ }^{\circ} \mathrm{C}$ (Fig. 3). In all cases, the increase in $\left[\mathrm{Glc}_{\mathrm{eq}}\right.$ ] was linear over time during the measurement period (from 0.5 to $2 \mathrm{~h}$ ) (Fig. 3) 
and the results were analyzed using Eq. 2. Most importantly, the slopes $\left(n v_{\left(\mathrm{H}_{2} \mathrm{O}_{2}\right)}\right)$ and intercepts $\left(n\left[\mathrm{H}_{2} \mathrm{O}_{2}\right]_{(t=0)}\right)$ were independent on the concentrations of $\operatorname{Tr} \mathrm{LPMO} 9 \mathrm{~A}$ and BMCC. On the other hand, both slope and intercept increased with increasing concentration of LF. Supplementation of the reactions with HRP $(1.0 \mu \mathrm{M})$ totally abolished the release of soluble products and no radioactivity was released in experiments without TrLPMO9A or LF (Fig. 3). Supplementation of the TrLPMO9A/BMCC/ LF reactions with $\mathrm{H}_{2} \mathrm{O}_{2}(20 \mu \mathrm{M})$ caused an activity burst that was reflected in an increased intercept but had no effect on the rate of further Glc $_{\text {eq }}$ formation $(0.50 \pm 0.03$ versus $0.52 \pm 0.05 \mu \mathrm{M} \mathrm{Glc} \mathrm{eq} \mathrm{min}^{-1}$ ) (Fig. 3). Collectively, these results suggest that the formation of $\mathrm{H}_{2} \mathrm{O}_{2}$ governs the steady-state rate of soluble product formation without being dependent on TrLPMO9A or cellulose concentration, while the initial activity burst is caused by the $\mathrm{H}_{2} \mathrm{O}_{2}$ present in the LF before the addition of LPMO.

\section{Stoichiometry of TrLPMO9A reaction}

To derive the values of $\left[\mathrm{H}_{2} \mathrm{O}_{2}\right]_{(t=0)}$ and $v_{\left(\mathrm{H}_{2} \mathrm{O}_{2}\right)}$ from the kinetics of $\mathrm{Glc}_{\mathrm{eq}}$ formation, one must know an average number of $\mathrm{Glc}_{\mathrm{eq}}$ released per one molecule of $\mathrm{H}_{2} \mathrm{O}_{2}$ consumed (i.e., parameter $n$ in Eq. 2). The $n$ can be measured through detailed kinetic characterization of $\mathrm{H}_{2} \mathrm{O}_{2}$-driven degradation of polysaccharides as has been done for $S m L P M O 10 A$ [48]. Unfortunately, the specific radioactivity of our BMCC preparation was not sufficiently high to permit detailed kinetic characterization of its $\mathrm{H}_{2} \mathrm{O}_{2}$-driven degradation by TrLPMO9A. Therefore, we estimated the value of $n$ using alternative approaches. Comparison of the rates of $\mathrm{NAG}_{\mathrm{eq}}$ formation measured using the $S m L P M O 10 A / C N W s$ system and $\mathrm{Glc}_{\text {eq }}$ formation measured using the TrLPMO9A/BMCC system suggested $n=2.1 \pm 0.3$ for the TrLPMO9A/BMCC system (Additional file 1: Fig. S4) at $25{ }^{\circ} \mathrm{C}$. An increase in intercept upon supplementation of TrLPMO9A/BMCC/ LF reactions with $\mathrm{H}_{2} \mathrm{O}_{2}$ (Fig. 3) provides an alternative approach for measuring stoichiometry. Of note, the latter approach can also be used at $50{ }^{\circ} \mathrm{C}$. Supplementation of $\operatorname{TrLPMO9A/BMCC/LF~reactions~(before~the~experiment~}$ the LF was pre-incubated at $50{ }^{\circ} \mathrm{C}$ for $24 \mathrm{~h}$ ) with $\mathrm{H}_{2} \mathrm{O}_{2}$ $(10-50 \mu \mathrm{M})$ caused an increase in the initial burst of Glc $_{\text {eq }}$ release with no influence on the later, linear release of $\mathrm{Glc}_{\text {eq }}$ in time (Fig. 4a). Intercept values obtained from linear regression analysis of data in Fig. 4a scaled linearly with the concentration of added $\mathrm{H}_{2} \mathrm{O}_{2}$ (Fig. 4b). The slope of this linear dependency suggested the value of $n=1.32 \pm 0.11$ for the TrLPMO9A/BMCC system at $50{ }^{\circ} \mathrm{C}$ and this figure was used throughout this study. Note, that the $n$ shall not be confused with the average degree of polymerization of soluble products since the latter depends on the probability of an oxidized group being in soluble fraction, which is 0.5 for SmLPMO10A/ CNW [48] but not known for the TrLPMO9A/BMCC system. Regarding the purposes of this study, it is important and enough to know that an average of 1.32 soluble $\mathrm{Glc}_{\mathrm{eq}}$ are released from BMCC per one molecule of $\mathrm{H}_{2} \mathrm{O}_{2}$ consumed by TrLPMO9A.

\section{Rate of $\mathrm{H}_{2} \mathrm{O}_{2}$ formation and accumulation upon incubation of $\mathrm{LF}$ at $50^{\circ} \mathrm{C}$}

To assess redox properties under typical industrial bioprocessing conditions, we pre-incubated $\mathrm{LF}$ at $50{ }^{\circ} \mathrm{C}$ in
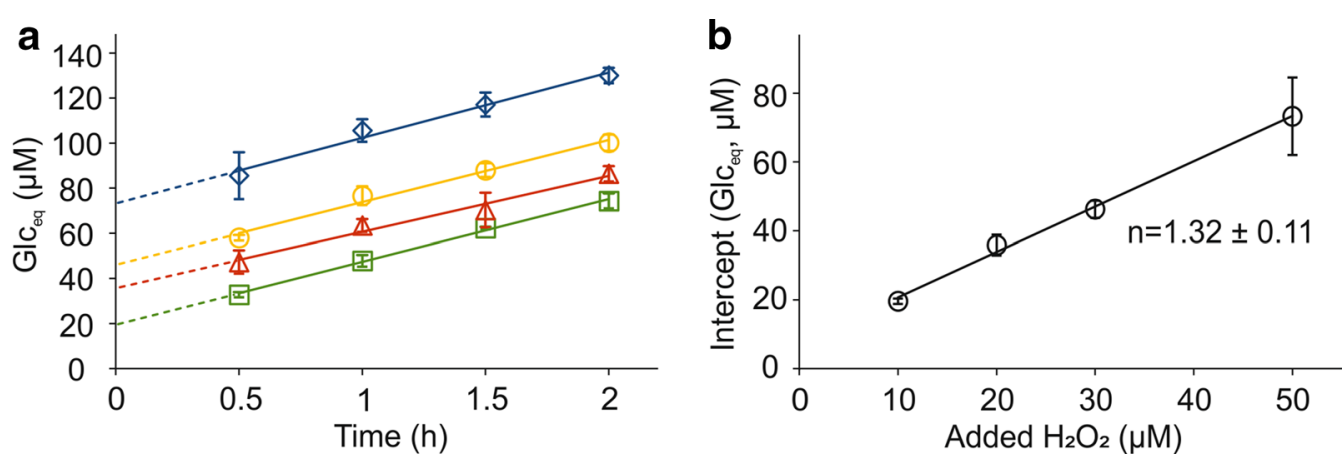

Fig. 4 Stoichiometry of the $\operatorname{Tr} \mathrm{LPMO} A \mathrm{~A}$ reaction at $50^{\circ} \mathrm{C}$. Reactions were made in $50 \mathrm{mM}$ sodium acetate $(\mathrm{pH} 5.0)$ at $50^{\circ} \mathrm{C}$. The concentrations of BMCC, LF and TrLPMO9A were $0.6 \mathrm{~g} \mathrm{~L}^{-1}, 10 \%(\mathrm{~V} / \mathrm{V})$ and $0.5 \mu \mathrm{M}$, respectively. Before use in the LPMO reaction, the LF was pre-incubated at $50^{\circ} \mathrm{C}$ for $24 \mathrm{~h}$. All reactions were supplemented with $\mathrm{H}_{2} \mathrm{O}_{2}(10-50 \mu \mathrm{M}$, final concentrations) just before starting the reaction by addition of TrLPMO9A. Error bars represent S.D. and are from at least two independent measurements. a Time curves for the formation of soluble products (expressed in glucose equivalents, $\mathrm{Gl}_{e q}$ ) upon incubation of BMCC with TrLPMO9A in the presence of externally added $\mathrm{H}_{2} \mathrm{O}_{2}$. Solid lines show linear regression of the data according to Eq. 2. b Dependency of intercept values obtained from linear regression of the data shown in panel A on the concentration of added $\mathrm{H}_{2} \mathrm{O}_{2}$. The solid line shows linear regression of the data and the slope of the line suggests stoichiometry of $1.32 \pm 0.11 \mathrm{Gl} \mathrm{C}_{\mathrm{eq}} / \mathrm{H}_{2} \mathrm{O}_{2}$ for the TrLPMO9A/ BMCC system 
the dark without stirring for time-periods ranging from 0.5 to $96 \mathrm{~h}$, aerobically. After pre-incubation, an aliquot of LF was added ( $10 \%$ or $20 \% \mathrm{v} / \mathrm{v})$ to BMCC followed by the addition of TrLPMO9A to start the LPMO reaction. The formation of $\mathrm{Glc}_{\mathrm{eq}}$ was linear in time (Fig. 5a) and the rate of $\mathrm{Glc}_{\mathrm{eq}}$ formation was independent of the concentration of TrLPMO9A (Additional file 1: Fig. S5). The time curves were fitted to Eq. 2 and the values of slopes and intercepts were converted to the values of $v_{\left(\mathrm{H}_{2} \mathrm{O}_{2}\right)}$ and $\left[\mathrm{H}_{2} \mathrm{O}_{2}\right]_{(t=0)}$, respectively, using $n=1.32$. The $\left[\mathrm{H}_{2} \mathrm{O}_{2}\right]_{(t=0)}$ increased (Fig. 5b) while $v_{\left(\mathrm{H}_{2} \mathrm{O}_{2}\right)}$ decreased

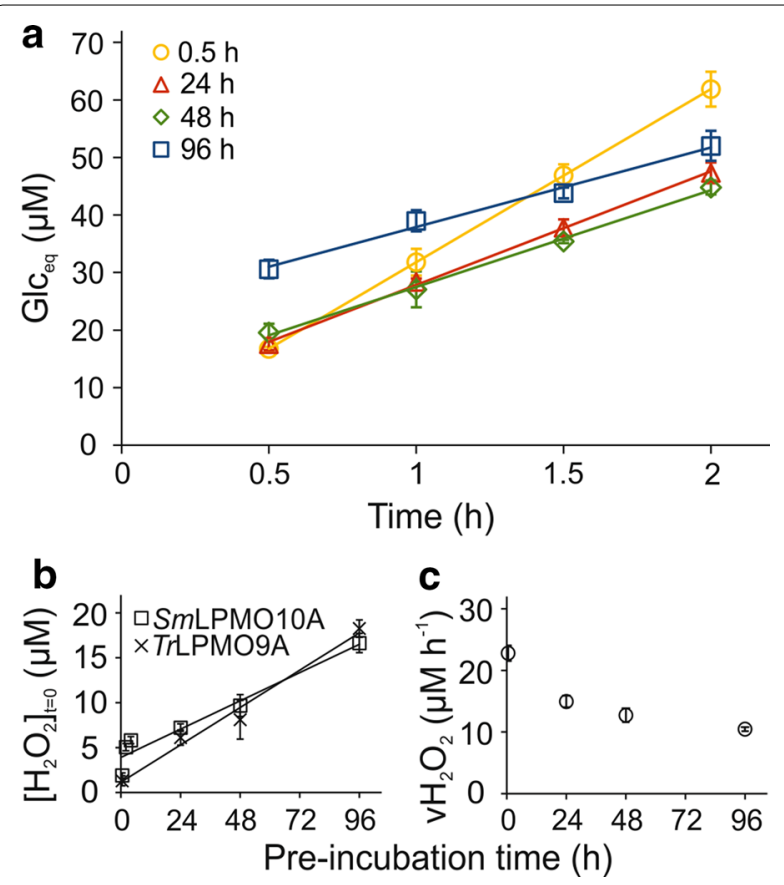

Fig. 5 Dependence of the $\left[\mathrm{H}_{2} \mathrm{O}_{2}\right]_{t=0}$ and $v_{\left(\mathrm{H}_{2} \mathrm{O}_{2}\right)}$ on pre-incubation time of LF at $50^{\circ} \mathrm{C}$. Reactions were made in $50 \mathrm{mM}$ sodium acetate ( $\mathrm{pH} \mathrm{5.0)}$ at $50^{\circ} \mathrm{C}$. The concentration of BMCC was $0.6 \mathrm{~g} \mathrm{~L}^{-1}$ and that of LF was $10 \%(\mathrm{v} / \mathrm{v})$. a Time curves of the formation of soluble products (expressed in glucose equivalents, $\mathrm{Gl}_{\mathrm{eq}}$ ) upon incubation of BMCC with $T r L P M O 9 A$ in the presence of $L F$ that was pre-incubated at $50^{\circ} \mathrm{C}$ for different time (as defined on the plot). Shown are average values, and S.D, obtained from experiments with TrLPMO9A concentrations of $0.1 \mu \mathrm{M}, 0.2 \mu \mathrm{M}$, or $0.5 \mu \mathrm{M}$ (see Additional file 1: Fig. S5 for the individual curves). Solid lines show linear regression of the data according to Eq. 2. b, $\mathbf{c}$ Dependence of (b) the $\left[\mathrm{H}_{2} \mathrm{O}_{2}\right]_{t=0}$ and (c) the $v_{\left(\mathrm{H}_{2} \mathrm{O}_{2}\right)}$, on pre-incubation time of $\mathrm{LF}$ at $50^{\circ} \mathrm{C}$. The values of $\left[\mathrm{H}_{2} \mathrm{O}_{2}\right]_{t=0}$ and $v_{\left(\mathrm{H}_{2} \mathrm{O}_{2}\right)}$ were found by fitting the data in $\mathbf{a}$ to Eq. 2 and using a stoichiometry of $1.32 \mathrm{Glce}_{\mathrm{eq}} / \mathrm{H}_{2} \mathrm{O}_{2}$. The values of $\left[\mathrm{H}_{2} \mathrm{O}_{2}\right]_{t=0}$ were also measured using an alternative approach (designated with $S m L P M O 10 A$ on $\mathbf{b}$ ) where LF was pre-incubated at $50^{\circ} \mathrm{C}$ but LPMO reaction was done at $25^{\circ} \mathrm{C}$ using the $\mathrm{SmLPMO10/CNW}$ system and short reaction times (Additional file 1: Fig S7). Solid lines in panel B show best-fits of the linear regression analysis. Error bars represent S.D. and are from three independent measurements each made at different concentration of TrLPMO9A (Additional file 1: Fig. S5)
(Fig. 5c) with pre-incubation time of LF. Corresponding results obtained with $20 \% \mathrm{LF}$ in the LPMO reaction are shown in Additional file 1: Fig. S6. Note that the rate of $\mathrm{H}_{2} \mathrm{O}_{2}$ formation in LF is strongly dependent on temperature. The $v_{\left(\mathrm{H}_{2} \mathrm{O}_{2}\right)}$ values derived from experiments with 0.5 -h pre-incubation and $10 \% \mathrm{LF}$ were $1.5 \pm 0.2 \mu \mathrm{M} \mathrm{h}^{-1}$ (Fig. 2c) and $22.7 \pm 1.2 \mu \mathrm{M} \mathrm{h}^{-1}$ (Fig. 5c) at $25{ }^{\circ} \mathrm{C}$ and $50{ }^{\circ} \mathrm{C}$, respectively. This difference in rates translates to a $\mathrm{Q}_{10}$ value of 3.0.

We note that determination of $\left[\mathrm{H}_{2} \mathrm{O}_{2}\right]_{(t=0)}$ values using the values of intercepts obtained by analysis of linear regions of progress curves according to Eq. 2 may be complicated for the systems with low $\left[\mathrm{H}_{2} \mathrm{O}_{2}\right]_{(t=0)}$ and high $v_{\left(\mathrm{H}_{2} \mathrm{O}_{2}\right)}$ values. Obviously, the high concentration of $\mathrm{H}_{2} \mathrm{O}_{2}$ produced during LPMO reaction affects precise measurement of low intercept values (see data with 0.5 -h pre-incubation of LF in Fig. 5a as an example). Therefore, the $\left[\mathrm{H}_{2} \mathrm{O}_{2}\right]_{(t=0)}$ values were also measured using an alternative approach where the LF was preincubated at $50{ }^{\circ} \mathrm{C}$ but the LPMO reaction was made at $25^{\circ} \mathrm{C}$ using the $S m L P M O 10 \mathrm{~A} / \mathrm{CNW}$ system and very short reaction times (up to $10 \mathrm{~min}$ ). In these conditions, the amount of $\mathrm{H}_{2} \mathrm{O}_{2}$ produced during LPMO reaction is negligible compared to its initial amount and Eq. 1 simplifies to Eq. 3.

$$
\left[\mathrm{NAG}_{\mathrm{eq}}\right]=n\left[\mathrm{H}_{2} \mathrm{O}_{2}\right]_{(t=0)}\left(1-\mathrm{e}^{-k_{(\mathrm{LPMO})}^{\mathrm{obs}}}\right)
$$

The time curves of $\mathrm{NAG}_{\mathrm{eq}}$ formation were analyzed using non-linear regression according to Eq. 3 (Additional file 1: Fig. S7) and the $\left[\mathrm{H}_{2} \mathrm{O}_{2}\right]_{(t=0)}$ values were found from the plateau values of $\mathrm{NAG}_{\mathrm{eq}}$ formation using $n=4$. Of note, the shape of the time curves suggested that the SmLPMO10A priming reduction efficiency of LF decreased with pre-incubation of LF and $100-\mu \mathrm{M}$ ascorbic acid was added to ensure efficient priming (Additional file 1: Fig. S7). The $\left[\mathrm{H}_{2} \mathrm{O}_{2}\right]_{(t=0)}$ found using short times of LPMO reaction and analysis according to Eq. 3 were similar to those found using longer LPMO reactions and analysis according to Eq. 2 (Fig. 5b). In both cases, the $\left[\mathrm{H}_{2} \mathrm{O}_{2}\right]_{(t=0)}$ seemed to scale linearly with pre-incubation time with the slope (i.e. the rate of $\mathrm{H}_{2} \mathrm{O}_{2}$ accumulation in LF during pre-incubation) about $0.15-\mu \mathrm{M} \mathrm{H}_{2} \mathrm{O}_{2} \mathrm{~h}^{-1}$ (or 1.5- $\mu \mathrm{M} \mathrm{H}_{2} \mathrm{O}_{2} \mathrm{~h}^{-1}$ when extrapolated to $100 \% \mathrm{LF}$ ) (Fig. $5 \mathrm{~b}$ ). This rate of $\mathrm{H}_{2} \mathrm{O}_{2}$ accumulation in LF is far lower than the rate of its formation in LF (Fig. 5c), suggesting that $\mathrm{H}_{2} \mathrm{O}_{2}$ is an intermediate in LF oxidation, supporting the conclusion derived from the pre-incubation experiments at $25^{\circ} \mathrm{C}$ with the $S m L P M O 10 A / C N W$ system (Fig. 2). 


\section{Discussion}

Since their discovery as oxidative enzymes [5], LPMOs have been a subject of intensive research. Still, the nature of the true co-substrate of LPMOs is a matter of scientific debate. The nature of the co-substrate (i.e., $\mathrm{O}_{2}$ or $\mathrm{H}_{2} \mathrm{O}_{2}$ ) that governs the LPMO kinetics under our experiment conditions is of utmost importance regarding the interpretation of the data presented here. Most importantly, we observed that LF-driven formation of soluble products from cellulose was independent of the concentration of TrLPMO9A (Fig. 3 and Additional file 1: Fig. S5) and the concentrations of cellulose substrate (Fig. 3) in the concentration range studied. This suggests that the ratelimiting step for the release of soluble products from cellulose is independent of the LPMO, a suggestion which is supported by the observation that the rate of chitin degradation by $S m L P M O 10 A$ also was independent of the enzyme concentration.

A number of different scenarios have been proposed for $\mathrm{O}_{2}$-driven degradation of polysaccharides by LPMOs $[27,28]$ but in all these cases, the rate is expected to depend on enzyme and/or polysaccharide concentration. Catalysis involving insoluble polysaccharides takes place at a solid-liquid interface and two saturation scenarios are possible, saturation of the enzyme with substrate (as in the conventional Michaelis-Menten mechanism) and saturation of substrate with enzyme (also known as the inversed Michaelis-Menten mechanism) [70]. Further increase of substrate concentration in the conditions where enzyme is already saturated with substrate will not increase the rate; however, increasing the enzyme concentration in these conditions should increase the rate. On the other hand, a further increase of the enzyme concentration in conditions where binding sites on the polymer surface are saturated with enzyme will not increase the rate; however, increase of the substrate concentration under such conditions should increase the rate. Thus, our observations cannot be ascribed to saturating conditions.

Cannella et al. proposed that pigment-derived excited electrons are responsible for the boosting effect of light on the degradation of cellulose by LPMOs $[71,72]$ Therefore, one may speculate that formation of "excited electrons" in LF is responsible for supporting LPMO activity as depicted in Fig. 6a. This scenario would be in accordance with the observed independency of the reaction rate on the concentration of LPMO and polysaccharide as the formation of such "excited electrons" could be a ratelimiting intrinsic property of the LF (note that reaction rates do depend on the amount of LF, Figs. 1, 3). Inhibition of LPMO by HRP can, in principle, be explained by the use of these electrons in the HRP reaction. However, such an "excited electron" scenario cannot explain the activity burst observed upon supplementation of an
LPMO reaction with $\mathrm{H}_{2} \mathrm{O}_{2}$ (Figs. 3, 4). Importantly, the observed increase in product formation upon addition of $\mathrm{H}_{2} \mathrm{O}_{2}$ scaled linearly with the concentration of added $\mathrm{H}_{2} \mathrm{O}_{2}$ (Fig. 4b). Further considering the results of the experiment with added $\mathrm{H}_{2} \mathrm{O}_{2}$, it is difficult to explain how a strong oxidant like $\mathrm{H}_{2} \mathrm{O}_{2}$ can support the formation of strong reductants like "excited electrons".

On the other hand, our observations can readily be explained in the light of $\mathrm{H}_{2} \mathrm{O}_{2}$-driven LPMO catalysis (Fig. 6b). According to this scenario, the release of soluble LPMO products is governed by the $\mathrm{H}_{2} \mathrm{O}_{2}$ present in LF before the addition of the LPMO (burst, c.f $\left[\mathrm{H}_{2} \mathrm{O}_{2}\right]_{(t=0)}$ ) and by $\mathrm{H}_{2} \mathrm{O}_{2}$ formed during the LPMO reaction (steadystate, c.f $\left.v_{\left(\mathrm{H}_{2} \mathrm{O}_{2}\right)}\right)$. It is well known that polysaccharidefree LPMOs [46, 73], including TrLPMO9A [67, 74], can produce $\mathrm{H}_{2} \mathrm{O}_{2}$ in a futile oxidase reaction with $\mathrm{O}_{2}$. Importantly, the contribution of this route must be insignificant under our experimental conditions, as in this case the rate is expected to increase with increasing concentration of LPMO. All in all, our results suggest that the LPMO kinetics measured here reflect the presence of $\mathrm{H}_{2} \mathrm{O}_{2}$ and the rate of $\mathrm{H}_{2} \mathrm{O}_{2}$ formation in LF.

Numerous reports have shown that process samples of lignocellulose refining support LPMO activity $[7,30,31$, 36-38]. The positive effect on LPMO activity has been assigned to the electron donating ability of lignin and lignin-derived, mostly phenolic compounds. Here, we show that the LPMO supporting activity of LF is related not only to electron transfer to the LPMO but also to production of the LPMO co-substrate, $\mathrm{H}_{2} \mathrm{O}_{2}$. The large discrepancy between the rate of $\mathrm{H}_{2} \mathrm{O}_{2}$ formation (Figs. 2c, 5c) and $\mathrm{H}_{2} \mathrm{O}_{2}$ accumulation in LF (Figs. 2b, 5b) shows that $\mathrm{H}_{2} \mathrm{O}_{2}$ is an intermediate in LF oxidation. It is plausible that phenolic compounds present in LF are responsible for $\mathrm{H}_{2} \mathrm{O}_{2}$ scavenging [75]. This " $\mathrm{H}_{2} \mathrm{O}_{2}$ buffering" capacity is important regarding the stability of LPMOs as it prevents the accumulation of $\mathrm{H}_{2} \mathrm{O}_{2}$ at high concentrations that may lead to inactivation of the LPMO [46, 48, 76]. Still, the "first contact" of LPMOs with pre-treated biomass slurry may result in inactivation of a significant amount of LPMO. The concentration of $\mathrm{H}_{2} \mathrm{O}_{2}$ in LF (preincubated at $50{ }^{\circ} \mathrm{C}$ for $24 \mathrm{~h}$ ) was about $70 \mu \mathrm{M}$ (Fig. 5b, extrapolated to $100 \% \mathrm{LF}$ ). For example, $\mathrm{H}_{2} \mathrm{O}_{2}$-driven inactivation of polysaccharide-free SmLPMO10A proceeds with a second-order rate constant in the order of $10^{3} \mathrm{M}^{-1} \mathrm{~s}^{-1}$ (at $25^{\circ} \mathrm{C}, \mathrm{pH}$ 6.1) [48]. This translates to a half-life of only about $10 \mathrm{~s}$ for polysaccharide free $\mathrm{SmLP}$ MO10A in 70- $\mu \mathrm{M} \mathrm{H}_{2} \mathrm{O}_{2}$. Therefore, a significant fraction of the LPMO may be inactivated at the very start of the reaction, before binding of the LPMO to the polysaccharide substrate and LPMO-catalyzed reduction of $\left[\mathrm{H}_{2} \mathrm{O}_{2}\right]$. Obviously, more kinetic data about $\mathrm{H}_{2} \mathrm{O}_{2}$-driven catalysis and inactivation of LPMOs along with knowledge of 
a

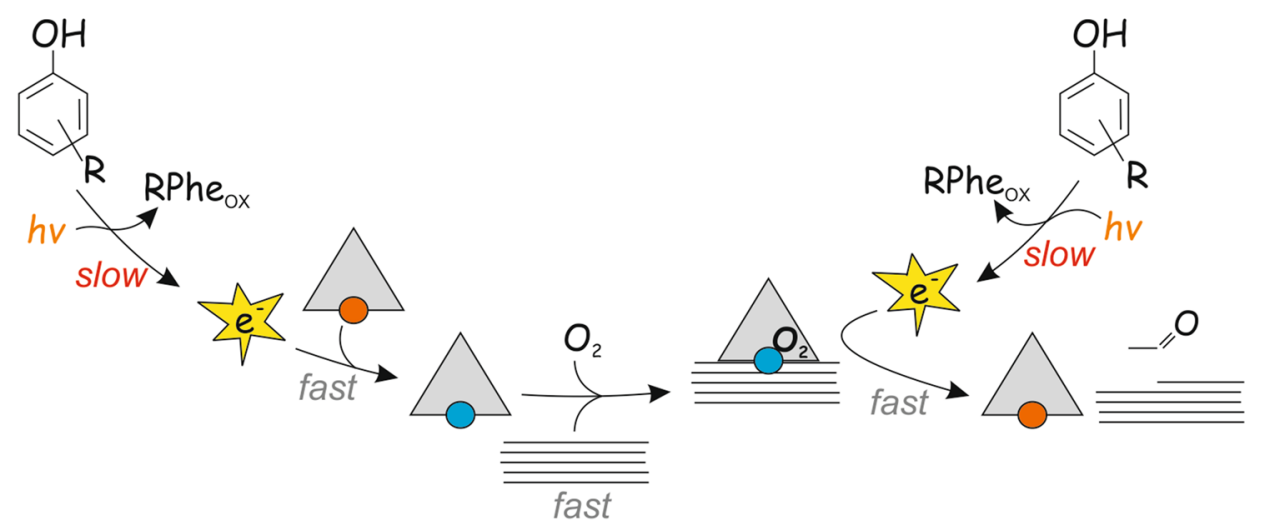

b
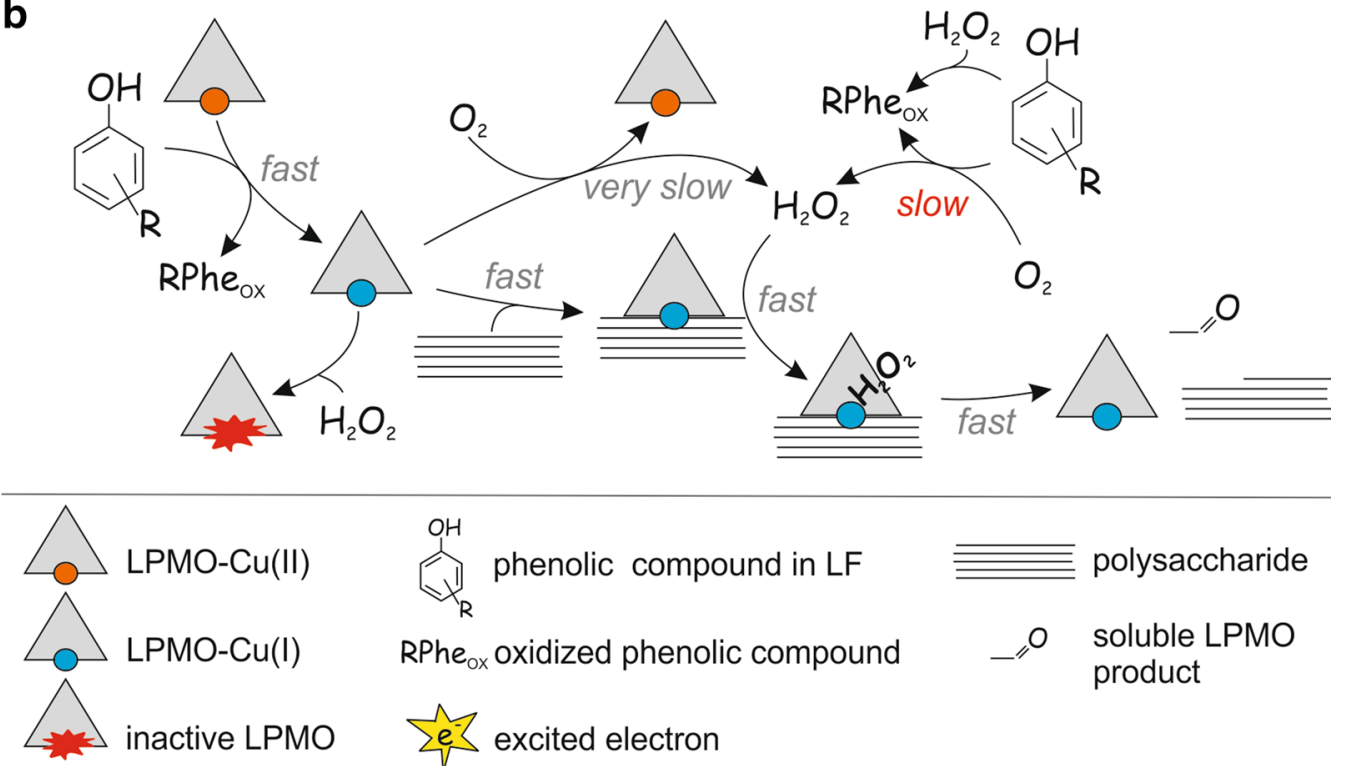

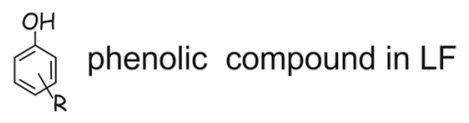

RPhe oxidized phenolic compound

$\sum e^{e} ?$ excited electron

Fig. 6 Possible mechanisms of liquid fraction (LF)-driven degradation of polysaccharides by LPMO. a According to this mechanism, LPMO uses $\mathrm{O}_{2}$ co-substrate and the LF (represented by a phenolic compound) drives the LPMO reaction by generating excited electrons that are used in a monooxygenase reaction. An analogous mechanism has been proposed by Cannela et al. to explain the LPMO activity-boosting effect of light in the presence of pigments [71]. The excited electrons generated in the LF are used for the initial reduction of the LPMO and subsequent catalysis via an LPMO/polysaccharide/ $\mathrm{O}_{2}$ ternary complex and including delivery of a second electron. The generation of excited electrons in LF may be stimulated (e.g., by light as shown in the scheme by hv) but stimulation is not a necessary assumption here. Note that many different mechanisms have been proposed for $\mathrm{O}_{2}$-driven catalysis but all these mechanisms assume the delivery of two electrons per one cleavage of glycosidic bond $[27,28]$. b According to this mechanism the LPMO uses $\mathrm{H}_{2} \mathrm{O}_{2}$ as co-substrate and the LF drives LPMO reaction by generating $\mathrm{H}_{2} \mathrm{O}_{2}$. The slow, LPMO-independent, formation of $\mathrm{H}_{2} \mathrm{O}_{2}$ in the reaction between $\mathrm{O}_{2}$ and $\mathrm{LF}$ is rate-limiting for $\mathrm{LPMO}$ catalysis. This mechanism also assumes the delivery of electrons by LF but here the electrons are used only in the "priming reduction" of the LPMO (from Cu(II) to Cu(I) form). Primed LPMO can catalyze a number of oxidative cleavages of glycosidic bonds until the polysaccharide free $L P M O$ happens to be re-oxidized, either by $\mathrm{O}_{2}$ or $\mathrm{H}_{2} \mathrm{O}_{2}[46,48,50]$. Note that re-oxidation of the $L P M O$ by $\mathrm{H}_{2} \mathrm{O}_{2}$ may lead to irreversible inactivation. Re-oxidation of a reduced $L P M O$ by $\mathrm{O}_{2}$ may also generate $\mathrm{H}_{2} \mathrm{O}_{2}$ [73]. However, in our experiments, the rates of the routes involving LPMO re-oxidation must have been insignificant compared to the rate of formation of soluble LPMO products since product formation was independent of the LPMO concentration

$\mathrm{H}_{2} \mathrm{O}_{2}$ concentrations in different biomass slurries are needed, to fully unravel this complex interplay of factors. It is worth noting that in all experiments in this study, LPMO activity was independent of the LPMO concentration, meaning that, even if some LPMO inactivation occurred, there was enough active enzyme left to utilize the available $\mathrm{H}_{2} \mathrm{O}_{2}$.
The rate of $\mathrm{H}_{2} \mathrm{O}_{2}$ production in LF decreased with preincubation time of LF under aerobic conditions but did not approach zero within the time frame of the experiment (Fig. 5c and Additional file 1: Fig. S6B). One may speculate that some compounds responsible for $\mathrm{H}_{2} \mathrm{O}_{2}$ production were depleted during the pre-incubation of LF at $50{ }^{\circ} \mathrm{C}$, whereas the concentration of other 
compounds remained near-constant. A detailed analysis of the very initial phase of the LF-driven LPMO reaction (Additional file 1: Fig. S7) showed that the priming reduction of SmLPMO10A becomes less efficient upon preincubation (c.f oxidation) of LF at $50{ }^{\circ} \mathrm{C}$. This indicates that the compounds in LF that are depleted during the pre-incubation may also be good priming reductants of LPMO. However, the precise chemical nature of the compounds in LF that are responsible for the LPMO priming reduction and $\mathrm{H}_{2} \mathrm{O}_{2}$ production/depletion remains to be studied. Although we removed divalent metals from substrates and buffers using treatment with EDTA and Chelex ${ }^{\circledR} 100$ resin, metal ions possibly present in LF [77] may contribute to the rate of $\mathrm{H}_{2} \mathrm{O}_{2}$ formation and $\mathrm{H}_{2} \mathrm{O}_{2}$ stability in LF.

Of note, the liquid fractions of hydrothermal pretreatment can be inhibitory for glycoside hydrolases. The main components responsible for the inhibition are hemicelluloses-derived oligosaccharides [4, 42, 78, 79], but the inhibition by phenolic compounds has also been demonstrated $[4,42,43,45,79,80]$. Therefore, the overall effect of liquid fraction on lignocellulose degradation depends on the relative contributions of its inhibiting and activating effects, which in turn depend on the composition of the enzyme cocktail and the type of pretreatment. The closest alternative to hydrothermal pretreatment is dilute acid treatment, and generally similar effects could be expected from the corresponding liquid fractions. Pretreatments that lead to extensive delignification may not support LPMO activity since the soluble lignin-containing liquor is usually removed before enzymatic hydrolysis. Based on the present findings, further studies of the relationships between the method of pretreatment and LPMO activity in subsequent enzymatic processing are of interest.

The rate of $\mathrm{H}_{2} \mathrm{O}_{2}$ formation in LF was strongly dependent on temperature with an estimated $\mathrm{Q}_{10}$ around 3.0. The $Q_{10}$ value found here seems to be in accordance with a recently reported effect of temperature on the half-life of $\mathrm{O}_{2}$ in a slurry of hydrothermally pre-treated wheat straw [81]. From the data in Peciulyte et al., one can estimate a half-life of $\mathrm{O}_{2}$ of about $1 \mathrm{~h}$ at $50{ }^{\circ} \mathrm{C}$ [81]. This translates to a rate constant of $\mathrm{O}_{2}$ consumption of $0.69 \mathrm{~h}^{-1}$, which in turn translates to a rate of $\mathrm{O}_{2}$ consumption of $140 \mu \mathrm{M} \mathrm{h}^{-1}$ (assuming an ambient $\mathrm{O}_{2}$ concentration of $0.2 \mathrm{mM}$ ). This value is in the same range as the rates of $\mathrm{H}_{2} \mathrm{O}_{2}$ formation in LF at $50{ }^{\circ} \mathrm{C}$ shown in Fig. $5 \mathrm{c}$ (after extrapolation to $100 \% \mathrm{LF}$ ). Thus, the data on $\mathrm{H}_{2} \mathrm{O}_{2}$ formation in LF from the hydrothermal pre-treatment of wheat straw are in general accordance with the data of $\mathrm{O}_{2}$ consumption by the whole slurry of hydrothermally pre-treated wheat straw. Interestingly, Peciulyte et al. showed that the abiotic consumption of $\mathrm{O}_{2}$ in slurry was much faster than the diffusion of $\mathrm{O}_{2}$ into the slurry, suggesting that the availability of $\mathrm{O}_{2}$ may be rate-limiting for the oxidation of biomass components [81]. Apparently, the availability of $\mathrm{O}_{2}$ along with the amounts and chemical nature of the components in biomass slurries are key determinants of the rate of $\mathrm{H}_{2} \mathrm{O}_{2}$ formation and, thus, of LPMO activity and stability in biomass processing.

\section{Conclusions}

In this study, we have demonstrated that soluble compounds in the liquid fraction (LF) from hydrothermal pre-treatment of wheat straw support LPMOs with both, electrons and the $\mathrm{H}_{2} \mathrm{O}_{2}$ co-substrate under conditions that are commonly used in enzymatic biomass processing. Both, a bacterial chitin-active and a fungal celluloseactive LPMO were supported by $\mathrm{LF}$ and the $\mathrm{H}_{2} \mathrm{O}_{2}$ was produced in the LF in an LPMO-independent manner. Our results point to that $\mathrm{H}_{2} \mathrm{O}_{2}$ is an intermediate and not an end product in LF oxidation. This is important, since the further reduction of $\mathrm{H}_{2} \mathrm{O}_{2}$ prevents its accumulation, thus diminishing the probability of enzyme inactivation. The most probable candidates responsible for $\mathrm{H}_{2} \mathrm{O}_{2}$ production are phenolic compounds in LF but their exact chemical nature remains to be studied. Further studies shall also reveal the relationships between the LPMO supporting efficiency of liquid streams and the method of pre-treatment and type of biomass. The results presented here may also provide a basis for development of LPMObased methods for sensing $\mathrm{H}_{2} \mathrm{O}_{2}$ in complex redox-active environments.

The effect of LF on LPMO activity and on $\mathrm{H}_{2} \mathrm{O}_{2}$ levels may have a major effect on biomass conversion reactions, as illustrated by the studies of Müller et al. [76] on the enzymatic conversion of various types of biomasses with an LPMO-containing cellulase cocktail. For example, using $\mathrm{H}_{2} \mathrm{O}_{2}$ feeding under anaerobic conditions, Müller et al. found that the incorporation of fed $\mathrm{H}_{2} \mathrm{O}_{2}$ into LPMO products was almost stoichiometric when degrading Avicel, i.e., a relative clean substrate, whereas this stoichiometric relationship was not observed when using lignin-containing substrates [76]. Of note, these studies also led to the suggestion that current commercial cellulase cocktails may contain more LPMOs than needed to convert available $\mathrm{H}_{2} \mathrm{O}_{2}$ $[76,82]$, which is in accordance with the lack of enzyme concentration dependency found in the present study. Clearly, the interplay between biomass pretreatment and the efficiency of the subsequent enzymatic conversion process needs to be revisited in light of recent findings on LPMOs. It is important to note that phenolics and other soluble compounds in the LF, such as hemicellulose fragments, may inhibit the glycoside 
hydrolases in commercial enzyme cocktails and that the nature of pretreatment step, thus, may affect more than just LPMO functionality.

\section{Supplementary information}

Supplementary information accompanies this paper at https://doi. org/10.1186/s13068-019-1578-5.

Additional file 1: Table S1. PCR primers used for screening of T. reesei transformants. Fig. S1. SDS-PAGE analysis of purified TrLPMO9A. Fig. S2. Time curves of $N_{A G}$ formation at different concentrations of $S m L P M O 10 A$ in reactions with LF pre-incubated at $25^{\circ} \mathrm{C}$. Fig. S3. Solid fraction (SF) from hydrothermal pretreatment of wheat straw supports the degradation of chitin (CNWs) by SmLPMO10A. Fig. S4. Stoichiometry of the TrLPMO9A reaction at $25^{\circ} \mathrm{C}$. Fig. S5. Time curves of $\mathrm{Glc}$ eq formation at different concentrations of TrLPMO9A, LF and the time period of pre-incubation of LF at $50{ }^{\circ} \mathrm{C}$. Fig. S6. Dependence of the concentration of $\mathrm{H}_{2} \mathrm{O}_{2}\left(\left[\mathrm{H}_{2} \mathrm{O}_{2}\right]_{t=0}\right)$, and the rate of its formation $\left(\boldsymbol{v}_{\left(\mathrm{H}_{2} \mathrm{O}_{2}\right)}\right)$ in the liquid fraction (LF) on the time period of pre-incubation of $\mathrm{LF}$ at $50^{\circ} \mathrm{C}$. Fig. S7. Measuring of $\left[\mathrm{H}_{2} \mathrm{O}_{2}\right]_{t=0}$ after different times of pre-incubation of $\mathrm{LF}$ at $50{ }^{\circ} \mathrm{C}$ using $\mathrm{SmLPMO} 10 \mathrm{~A}$.

\section{Abbreviations}

AscA: ascorbic acid; BMCC: ${ }^{14} \mathrm{C}$-labeled bacterial microcrystalline cellulose; CNWs: ${ }^{14} \mathrm{C}$-labeled chitin nanowhiskers; EDTA: ethylenediaminetetraacetate; Glc $c_{\text {eq }}$ glucose equivalents; HRP: horseradish peroxidase; LF: liquid fraction from hydrothermal pretreatment of wheat straw; LPMO: Iytic polysaccharide monooxygenase; $\mathrm{NAG}_{\text {eq }}$ : $\mathrm{N}$-acetylglucosamine equivalents.

\section{Acknowledgements}

Riitta Isoniemi is acknowledged for carrying out the purification of TrLPMO9A.

\section{Authors' contributions}

PV conceived and coordinated the study. KK coordinated the hydrothermal pretreatment and post-pretreatment analyses. RK and PV made experiments with LPMOs. VP made hydrothermal pretreatment of wheat straw. NA and KM prepared TrLPMO9A. VGHE provided SmLPMO10A. VP, AB, JL, and JB analyzed the LF and solid fraction. PV, RK, NA, VP, KM, JL and VGHE wrote the manuscript. All authors read and approved the final manuscript.

\section{Funding}

This work was supported by the INNO INDIGO Partnership Programme Biobased Energy and by the Estonian Research Council (Grant PUT1024). VGHE was supported by Grant 268002 from the Research Council of Norway.

\section{Availability of data and materials \\ All data generated during the present study are included in this published article.}

\section{Ethics approval and consent to participate}

Not applicable.

\section{Consent for publication}

Not applicable.

\section{Competing interests}

The authors declare that they have no competing interests.

\section{Author details}

${ }^{1}$ Institute of Molecular and Cell Biology, University of Tartu, Tartu, Estonia. ${ }^{2}$ VTT Technical Research Centre of Finland Ltd, Espoo, Finland. ${ }^{3}$ Department of Biochemical Engineering (AVT.BioVT), RWTH Aachen University, Aachen, Germany. ${ }^{4}$ Norwegian University of Life Sciences (NMBU), Ås, Norway.

Received: 21 June 2019 Accepted: 24 September 2019

Published online: 08 October 2019

\section{References}

1. Pu Y, Hu F, Huang F, Davison BH, Ragauskas AJ. Assessing the molecular structure basis for biomass recalcitrance during dilute acid and hydrothermal pretreatments. Biotechnol Biofuels. 2013;6:15.

2. Cao G, Ximenes E, Nichols NN, Zhang L, Ladisch M. Biological abatement of cellulase inhibitors. Bioresour Technol. 2013;146:604-10.

3. Ko JK, Um Y, Park Y-C, Se J-H, Ki KH. Compounds inhibiting the bioconversion of hydrothermally pretreated lignocellulose. Appl Microbiol Biotechnol. 2015;99:4201-12

4. Zhai R, Hu J, Saddler JN. What are the major components in steam pretreated lignocellulosic biomass that inhibit the efficacy of cellulase enzyme mixtures? ACS Sustain Chem Eng. 2016;4:3429-36.

5. Vaaje-Kolstad G, Westereng B, Horn SJ, Liu Z, Zhai H, Sørlie M, Eijsink VGH. An oxidative enzyme boosting the enzymatic conversion of recalcitrant polysaccharides. Science. 2010;330:219-22.

6. Harris PV, Welner D, McFarland KC, Re E, Poulsen J-CN, Brown K, Salbo R, Ding H, Vlasenko E, Merino S, Xu F, Cherry J, Larsen S, Lo Leggio L. Stimulation of lignocellulosic biomass hydrolysis by proteins of glycoside hydrolase family 61: structure and function of a large, enigmatic family. Biochemistry. 2010;49:3305-16.

7. Hu J, Arantes V, Pribowo A, Gourlay K, Saddler JN. Substrate factors that influence the synergistic interaction of AA9 and cellulases during the enzymatic hydrolysis of biomass. Energy Environ Sci. 2014;7:2308-15.

8. Frommhagen M, Sforza S, Westphal AH, Visser J, Hinz SWA, Koetsier MJ, van Berkel WJH, Gruppen H, Kabel MA. Discovery of the combined oxidative cleavage of plant xylan and cellulose by a new fungal polysaccharide monooxygenase. Biotechnol Biofuels. 2015;8:101.

9. Martinez AT. How to break down crystalline cellulose. Science. 2016;352:1050-1.

10. Crouch LI, Labourel A, Walton PH, Davies GJ, Gilbert HJ. The contribution of non-catalytic carbohydrate binding modules to the activity of lytic polysaccharide monooxygenases. J Biol Chem. 2016;291:7439-49.

11. Bulakhov AG, Gusakov AV, Chekushina AV, Satrutdinov AD, Koshelev AV, Matys VY, Sinitsyn AP. Isolation of homogeneous polysaccharide monooxygenases from fungal sources and investigation of their synergism with cellulases when acting on cellulose. Biochemistry. 2016;81:530-7.

12. Chylenski P, Forsberg Z, Ståhlberg J, Varnai A, Lersch M, Bengtsson O, Sæbø S, Horn SJ, Eijsink VGH. Development of minimal enzyme cocktails for hydrolysis of sulfite-pulped lignocellulosic biomass. J. Biotechnol. 2017;246:16-23.

13. Chylenski P, Petrovic DM, Müller G, Dahlström M, Bengtsson O, Lersch M, Siika-aho M, Horn SJ, Eijsink VGH. Enzymatic degradation of sulfite-pulped softwoods and the role of LPMOs. Biotechnol Biofuels. 2017;10:177.

14. Ladeveze S, Haon M, Villares A, Cathala B, Grisel S, Herpoel-Gimbert I, Henrissat B, Berrin J-G. The yeast Geotrichum candidum encodes functional lytic polysaccharide monooxygenases. Biotechnol Biofuels. 2017:10:215.

15. Eibinger M, Ganner T, Bubner P, Rosker S, Kracher D, Haltrich D, Ludwig R, Plank H, Nidetzky B. Cellulose surface degradation by a lytic polysaccharide monooxygenase and its effect on cellulase hydrolytic efficiency. J Biol Chem. 2014;289:35929-38.

16. Eibinger M, Sattelkow J, Ganner T, Plank H, Nidetzky B. Single-molecule study of oxidative enzymatic deconstruction of cellulose. Nat. Commun. 2017;8:894

17. Pierce BC, Agger JW, Zhang Z, Wichmann J, Meyer AS. A comparative study on the activity of fungal lytic polysaccharide monooxygenases for the depolymerization of cellulose in soybean spent flakes. Carbohydr Res. 2017;449:85-94.

18. Du L, Ma L, Ma Q, Guo G, Han X, Xiao D. Hydrolytic boosting of lignocellulosic biomass by a fungal lytic polysaccharide monooxygenase, AnLPMO15g from Aspergillus niger. Ind Crop Prod. 2018;126:309-15.

19. Du J, Song W, Zhang X, Zhao J, Liu J, Qu Y. Differential reinforcement of enzymatic hydrolysis by adding chemicals and accessory proteins to high solid loading substrates with different pretreatments. Bioprocess Biosyst Eng. 2018:41:1153-63.

20. Sanhueza C, Carvajal G, Soto-Aguilar J, Lienqueo ME, Salazar O. The effect of a lytic polysaccharide monooxygenase and a xylanase from Gloephyllum trabeum on the enzymatic hydrolysis of lignocellulosic residues using a commercial cellulase. Enzym Microb Technol. 2018;113:75-82.

21. Couturier M, Ladeveze S, Sulzenbacher G, Ciano L, Fanuel M, Moreau C, Villares A, Cathala B, Chaspoul F, Frandsen KE, Labourel A, 
Herpöel-Gimbert I, Grisel S, Haon M, Lenfant N, Rogniaux H, Ropartz D, Davies GJ, Rosso M-N, Walton PH, Henrissat B, Berrin J-G. Lytic xylan oxidases from wood-decay fungi unlock biomass degradation. Nat Chem Biol. 2018;14:306-10.

22. Liu B, Krishnaswamyreddy S, Muraleedharan MN, Olson Å, Broberg A, Ståhlberg J, Sandgren M. Side-by-side biochemical comparison of two lytic polysaccharide monooxygenases from the white-rot fungus Heterobasidion irregulare on their activity against crystalline cellulose and glucomannan. PLoS ONE. 2018;13(9):e0203430.

23. Hu J, Tian D, Renneckar S, Saddler JN. Enzyme mediated nanofibrillation of cellulose by the synergistic actions of an endoglucanase, lytic polysaccharide monooxygenase (LPMO) and xylanase. Sci. Rep. 2018;8:3195.

24. Johansen KS. Discovery and industrial applications of lytic polysaccharide mono-oxygenases. Biochem Soc Trans. 2016;44:143-9.

25. Quinlan RJ, Sweeney MD, Lo Leggio L, Otten H, Poulsen J-CN, Johansen KS, Krogh KBRM, Jørgensen Cl, Tovborg M, Anthonsen A, Tryfona T, Walter CP, Dupree P, XU F, Davies GJ, Walton PH. Insights into the oxidative degradation of cellulose by a copper metalloenzyme that exploits biomass components. Proc Natl Acad Sci USA. 2011;108:15079-84.

26. Phillips CM, Beeson WT, Cate JH, Marletta MA. Cellobiose dehydrogenase and a copper-dependent polysaccharide monooxygenase potentiate cellulose degradation by Neurospora crassa. ACS Chem Biol. 2011;6:1399-406.

27. Meier KM, Jones SM, Kaper T, Hansson H, Koetsier MJ, Karkehabadi S, Solomon El, Sandgren M, Kelemen B. Oxygen activation by Cu LPMOs in recalcitrant carbohydrate polysaccharide conversion to monomer sugars. Chem Rev. 2018;118:2593-635.

28. Walton PH, Davies GJ. On the catalytic mechanisms of lytic polysaccharide monooxygenases. Curr Opin Chem Biol. 2016;31:195-207.

29. Frommhagen M, Westphal AH, van Berkel WJH, Kabel MA. Distinct substrate specificities and electron-donating systems of fungal lytic polysaccharide monooxygenases. Front Microbiol. 2018;9:1080.

30. Kracher D, Scheiblbrandner S, Felice AKG, BresImayr E, Preims M, Ludwicka K, Haltrich D, Eijsink VGH, Ludwig R. Extracellular electron transfer systems fuel cellulose oxidative degradation. Science. 2016;352:1098-101.

31. Frommhagen M, Koetsier MJ, Westphal AH, Visser J, Hinz SWA, Vincken J-P, van Berkel WJH, Kabel MA, Gruppen H. Lytic polysaccharide monooxygenases from Myceliophthora thermophila C1 differ in substrate preference and reducing agent specificity. Biotechnol Biofuels. 2016;9:186.

32. Frommhagen M, Mutte SK, Westphal AH, Koetsier MJ, Hinz SWA, Visser J, Vincken J-P, Weijers D, van Berkel WJH, Gruppen H, Kabel MA. Boosting LPMO-driven lignocelluloses degradation by polyphenol oxidase-activated lignin building blocks. Biotechnol Biofuels. 2017;10:121.

33. Frommhagen M, Westphal AH, Hilgers R, Koetsier MJ, Hinz SWA, Visser J, Gruppen H, van Berkel WJH, Kabel MA. Quantification of the catalytic performance of C1-cellulose-specific lytic polysaccharide monooxygenases. Appl Microbiol Biotechnol. 2018;102:1281-95.

34. Brenelli L, Squina F, Felby C, Cannella D. Laccase-derived lignin compounds boost cellulose oxidative enzymes AA9. Biotechnol Biofuels. 2018;11:10.

35. Hegnar OA, Petrovic DM, Bissaro B, Alfredsen G, Varnai A, Eijsink VGH. Characterization of a lytic polysaccharide monooxygenase from Gloephyllum trabeum shows a pH-dependent relationship between catalytic activity and hydrogen peroxide production. Appl Environ Microbiol. 2019:85:02612-8.

36. Rodriguez-Zuniga UF, Cannella D, Giordano RC, Giordano RLC, Jørgensen $\mathrm{H}$, Felby C. Lignocellulose pretreatment technologies affect the level of enzymatic cellulose oxidation by LPMO. Green Chem. 2015;17:2896-903.

37. Westereng B, Cannella D, Agger JW, Jørgensen H, Andersen ML, Eijsink VGH, Felby C. Enzymatic cellulose oxidation is linked to lignin by longrange electron transfer. Sci Rep. 2015;5:18561.

38. Muraleedharan MN, Zouraris D, Karantonis A, Topakas E, Sandgren M, Rova U, Christakopoulos P, Karnaouri A. Effect of lignin fractions isolated from different biomass sources on cellulose oxidation by fungal lytic polysaccharide monooxygenases. Biotechnol Biofuels. 2018;11:296.

39. Du B, Sharma LN, Becker C, Chen S-F, Mowery RA, van Walsum GP, Chambliss CK. Effect of varying feedstock-pretreatment chemistry combinations on the formation and accumulation of potentially inhibitory degradation products in biomass hydrolysates. Biotechnol Bioeng. 2010;107:430-40.
40. Rajan K, Carrier DJ. Characterization of rice straw prehydrolyzates and their effect on the hydrolysis of model substrates using commercial endo-cellulase, $\beta$-glucosidase and cellulase cocktail. ACS Sustain Chem Eng. 2014;2:2124-30.

41. Zhao J, Chen H. Stimulation of cellulases by small phenolic compounds in pretreated stover. J Agric Food Chem. 2014;62:3223-9.

42. Rasmussen H, Sørensen HR, Tanner D, Meyer AS. New pentose dimers with bicyclic moieties from pretreated biomass. RSC Adv. 2017;7:5206-13.

43. Rasmussen H, Tanner D, Sørensen HR, Meyer AS. New degradation compounds from lignocellulosic biomass pretreatment: routes for formation of potent oligophenolic enzyme inhibitors. Green Chem. 2017;19:464-73.

44. Wu J, Collins SRA, Elliston A, Wellner N, Dicks J, Roberts IN, Waldron KW. Release of cell wall phenolic esters during hydrothermal pretreatment of rice husk and rice straw. Biotechnol Biofuels. 2018;11:162.

45. Zhai R, Hu J, Saddler JN. Extent of enzyme inhibition by phenolics derived from pretreated biomass is significantly influenced by the size and carbonyl group content of phenolics. ACS Sustain Chem Eng. 2018;6:3823-9.

46. Bissaro B, Røhr ÅK, Skaugen M, Forsberg Z, Horn SJ, Vaaje-Kolstad G, Eijsink VGH. Oxidative cleavage of polysaccharides by monocopper enzymes depends on $\mathrm{H}_{2} \mathrm{O}_{2}$. Nat Chem Biol. 2017;10:1123-8.

47. Bissaro B, Varnai A, Røhr ÅK, Eijsink VGH. Oxidoreductases and reactive oxygen species in conversion of lignocellulosic biomass. Microbiol Mol Biol Rev. 2018;82:e00029-118.

48. Kuusk S, Bissaro B, Kuusk P, Forsberg Z, Eijsink VGH, Sørlie M, Väljamäe P. Kinetics of $\mathrm{H}_{2} \mathrm{O}_{2}$-driven degradation of chitin by a bacterial lytic polysaccharide monooxygenase. J Biol Chem. 2018;293:523-31.

49. Hangasky JA, lavarone AT, Marletta MA. Reactivity of $\mathrm{O}_{2}$ versus $\mathrm{H}_{2} \mathrm{O}_{2}$ with polysaccharide monooxygenases. Proc Natl Acad Sci USA. 2018;115:4915-20.

50. Kuusk S, Kont R, Kuusk P, Heering A, Sørlie M, Bissaro B, Eijsink VGH, Väljamäe P. Kinetic insights into the role of the reductant in $\mathrm{H}_{2} \mathrm{O}_{2}$-driven degradation of chitin by a bacterial lytic polysaccharide monooxygenase. J Biol Chem. 2019;294:1516-28.

51. Eijsink VGH, Petrovic D, Forsberg Z, Mekasha S, Røhr ÅK, Varnai A, Bissaro $B$, Vaaje-Kolstad G. On the functional characterization of lytic polysaccharide monooxygenases (LPMOs). Biotechnol Biofuels. 2019;12:58.

52. Kuusk S, Sørlie M, Väljamäe P. The predominant molecular state of bound enzyme determines the strength and type of product inhibition in the hydrolysis of recalcitrant polysaccharides by processive enzymes. J Biol Chem. 2015;290:11678-91.

53. Velleste R, Teugjas $H$, Väljamäe P. Reducing end-specific fluorescence labeled celluloses for cellulase mode of action. Cellulose. 2010;17:125-38.

54. Jalak J, Kurašin $M$, Teugjas $H$, Väljamäe $P$. Endo-exo synergism in cellulose hydrolysis revisited. J Biol Chem. 2012;287:28802-15.

55. Vaaje-Kolstad G, Houston DR, Riemen AHK, Eijsink VGH, van Aalten DMF. Crystal structure and binding properties of the Serratia marcescens chitinbinding protein CBP21. J Biol Chem. 2005;280:11313-9.

56. Colot HV, Park G, Turner GE, Ringelberg C, Crew CM, Litvinkova L, Weiss RL, Borkovich KA, Dunlap JC. A high-throughput gene knockout procedure for Neurospora reveals functions for multiple transcription factors. Proc Natl Acad Sci USA. 2006;103:10352-7.

57. Colabardini AC, Valkonen M, Huuskonen A, Siika-Aho M, Koivula A, Goldman GH, Saloheimo M. Expression of two novel $\beta$-glucosidases from Chaetomium atrobrunneum in Trichoderma reesei and characterization of the heterologous protein products. Mol Biotechnol. 2016;58:821-31.

58. Mach RL, Schindler M, Kubicek CP. Transformation of Trichoderma reesei based on hygromycin B resistance using homologous expression signals. Curr Genet. 1994;25:567-70.

59. Landowski CP, Huuskonen A, Wahl R, Westerholm-Parvinen A, Kanerva A, Hänninen AL, Salovuori N, Penttilä M, Natunen J, Ostermeier C, Helk B, Saarinen J, Saloheimo M. Enabling low cost biopharmaceuticals: a systematic approach to delete proteases from a well-known protein production host Trichoderma reesei. PLoS ONE. 2015;10:e0134723.

60. Bailey MJ, Tähtiharju J. Efficient cellulase production by Trichoderma reesei in continuous cultivation on lactose medium with a computer-controlled feeding strategy. Appl Microbiol Biotechnol. 2003;62:156-62.

61. Bailey $\mathbf{M}$, Nevalainen $\mathrm{H}$. Induction, isolation and testing of stable Trichoderma reesei mutants with improved production of solubiling cellulase. Enzym Microb Technol. 1981;3:153-7.

62. Bailey MJ, Biely P, Poutanen K. Interlaboratory testing of methods for assay of xylanase activity. J Biotechnol. 1992;23:257-70. 
63. Stålbrand $\mathrm{H}$, Siika-aho M, Tenkanen M, Viikari L. Purification and characterization of two beta-mannanases from Trichoderma reesei. J Biotechnol. 1993;29:229-42.

64. Goldschmid O. Ultraviolet spectra. In: Sarkanen KV, Ludwig CH, editors. Lignins: occurrence, formation, structure and reactions. Hoboken: Wiley; 1971. p. 241-98.

65. Sluiter JB, Ruiz RO, Scarlata CJ, Sluiter AD, Templeton DW. Compositional analysis of lignocellulosic feedstocks. 1. Review and description of methods. J Agric Food Chem. 2010:58:9043-53.

66. Tanghe M, Danneels B, Camattari A, Glieder A, Vandenberghe I, Devreese B, Stals I, Desmet T. Recombinant expression of Trichoderma reesei Cel61A in Pichia pastoris: optimizing yield and N-terminal processing. Mol Biotechnol. 2015:57:1010-7.

67. Guo Z-P, Duquesne S, Bozonnet S, Nicaud J-M, Marty A, O'Donohue MJ. Expressing accessory proteins in cellulolytic Yarrowia lipolytica to improve the conversion yield of recalcitrant cellulose. Biotechnol Biofuels. 2017; 10:298.

68. Hansson H, Karkehabadi S, Mikkelsen N, Douglas NR, Kim S, Lam A, Kaper T, Kelemen B, Meier KK, Jones SM, Solomon El, Sandgren M. High-resolution structure of lytic polysaccharide monooxygenase from Hypocrea jecorina reveals a predicted linker as an integral part of the catalytic domain. J Biol Chem. 2017;292:19099-109.

69. Song B, Li B, Wang X, Shen W, Park S, Collings C, Feng A, Smith SJ, Walton JD, Ding S-Y. Real-time imaging reveals that lytic polysaccharide monooxygenase promotes cellulase activity by increasing cellulose accessibility. Biotechnol Biofuels. 2018;11:41.

70. Kari J, Andersen M, Borch K, Westh P. An inverse Michaelis-Menten approach for interfacial enzyme kinetics. ACS Catal. 2017;7:4904-14.

71. Cannella D, Möllers KB, Frigaard N-U, Jensen PE, Bjerrum MJ, Johansen KS, Felby C. Light-driven oxidation of polysaccharides by photosynthetic pigments and a metalloenzyme. Nat Commun. 2016;7:11134.

72. Möllers KB, Mikkelsen H, Simonsen TI, Cannella D, Johansen KS, Bjerrum $\mathrm{MJ}$, Felby $\mathrm{C}$. On the formation and role of reactive oxygen species in lightdriven LPMO oxidation of phosphoric acid swollen cellulose. Carbohydr Res. 2017:448:182-6.

73. Kittl R, Kracher D, Burgstaller D, Haltrich D, Ludwig R. Production of four Neurospora crassa lytic polysaccharide monooxygenases in Pichia pastoris monitored by a fluorimetric assay. Biotechnol Biofuels. 2012;5:79.
74. Danneels B, Tanghe M, Desmet T. Structural features on the substratebinding surface of fungal lytic polysaccharide monooxygenases determine their oxidative regioselectivity. Biotechnol J. 2019;14:1800211.

75. Sroka Z, Cisowski W. Hydrogen peroxide scavenging, antioxidant and anti-radical activity of some phenolic acids. Food Chem Toxicol. 2003:41:753-8.

76. Müller G, Chylenski P, Bissaro B, Eijsink VGH, Horn SJ. The impact of hydrogen peroxide supply on LPMO activity and overall saccharification efficiency of a commercial cellulase cocktail. Biotechnol Biofuels. 2018;11:209.

77. Le DM, Sørensen HR, Knudsen NO, Schjoerring JK, Meyer AS. Biorefining of wheat straw: accounting for the distribution of mineral elements in pretreated biomass by an extended pretreatment-severity equation. Biotechnol Biofuels. 2014;7:141.

78. Kont R, Kurašin M, Teugjas H, Väljamäe P. Strong cellulase inhibitors from hydrothermal pretreatment of wheat straw. Biotechnol Biofuels. 2013;6:135

79. Rajan K, Carrier DJ. Insights into exo-cellulase inhibition by the hot water hydrolyzates of rice straw. ACS Sustainable Chem. Eng. 2016;4:3627-33.

80. Zhai R, Hu J, Saddler JN. Understanding the slowdown of whole slurry hydrolysis of steam pretreated lignocellulosic woody biomass catalyzed by an up-to-date enzyme cocktail. Sustain Energy Fuels. 2018;2:1048-56.

81. Peciulyte A, Samuelsson L, Olsson L, McFarland KC, Frickmann J, Østergård L, Halvorsen R, Scott BR, Johansen KS. Redox processes acidify and decarboxylate steam-pretreated lignocellulosic biomass and are modulated by LPMO and catalase. Biotechnol Biofuels. 2018;11:165.

82. Chylenski P, Bissaro B, Sørlie M, Røhr ÅK, Varnai A, Horn SJ, Eijsink VGH. Lytic polysaccharide monooxygenases in enzymatic processing of lignocellulosic biomass. ACS Catal. 2019;9:4970-91.

\section{Publisher's Note}

Springer Nature remains neutral with regard to jurisdictional claims in published maps and institutional affiliations.
Ready to submit your research? Choose BMC and benefit from:

- fast, convenient online submission

- thorough peer review by experienced researchers in your field

- rapid publication on acceptance

- support for research data, including large and complex data types

- gold Open Access which fosters wider collaboration and increased citations

- maximum visibility for your research: over 100M website views per year

At BMC, research is always in progress.

Learn more biomedcentral.com/submissions 